\title{
Implementing the 2009 Institute of Medicine recommendations on resident physician work hours, supervision, and safety
}

This article was published in the following Dove Press journal:

Nature and Science of Sleep

21 June 2011

Number of times this article has been viewed

\author{
Alexander B Blum' \\ Sandra Shea ${ }^{2}$ \\ Charles A Czeisler ${ }^{3,4}$ \\ Christopher P Landrigan ${ }^{3-5}$ \\ Lucian Leape ${ }^{6}$ \\ 'Department of Health and \\ Evidence Policy, Mount Sinai School \\ of Medicine, New York, NY, USA; \\ ${ }^{2}$ Committee of Interns and Residents, \\ SEIU Healthcare Division, Service \\ Employees International Union, New \\ York, NY, USA; ${ }^{3}$ Harvard Work Hours, \\ Health and Safety Group, Division \\ of Sleep Medicine, Harvard Medical \\ School, Boston, MA, USA; ${ }^{4}$ Division \\ of Sleep Medicine, Department of \\ Medicine, Brigham and Women's \\ Hospital, Harvard Medical School, \\ Boston, MA, USA; ${ }^{5}$ Division of General \\ Pediatrics, Department of Medicine, \\ Children's Hospital Boston, Harvard \\ Medical School, Boston, MA, USA; \\ ${ }^{6}$ Department of Health Policy and \\ Management, Harvard School of \\ Public Health, Boston, MA, USA
}

Correspondence: Charles A Czeisler Division of Sleep Medicine, Brigham and Women's Hospital, Harvard Medical School, 22I Longwood Avenue, Suite 438, Boston, MA 02II5, USA

Email charles_czeisler@hms.harvard.edu
Abstract: Long working hours and sleep deprivation have been a facet of physician training in the US since the advent of the modern residency system. However, the scientific evidence linking fatigue with deficits in human performance, accidents and errors in industries from aeronautics to medicine, nuclear power, and transportation has mounted over the last 40 years. This evidence has also spawned regulations to help ensure public safety across safety-sensitive industries, with the notable exception of medicine.

In late 2007, at the behest of the US Congress, the Institute of Medicine embarked on a yearlong examination of the scientific evidence linking resident physician sleep deprivation with clinical performance deficits and medical errors. The Institute of Medicine's report, entitled "Resident duty hours: Enhancing sleep, supervision and safety", published in January 2009, recommended new limits on resident physician work hours and workload, increased supervision, a heightened focus on resident physician safety, training in structured handovers and quality improvement, more rigorous external oversight of work hours and other aspects of residency training, and the identification of expanded funding sources necessary to implement the recommended reforms successfully and protect the public and resident physicians themselves from preventable harm.

Given that resident physicians comprise almost a quarter of all physicians who work in hospitals, and that taxpayers, through Medicare and Medicaid, fund graduate medical education, the public has a deep investment in physician training. Patients expect to receive safe, high-quality care in the nation's teaching hospitals. Because it is their safety that is at issue, their voices should be central in policy decisions affecting patient safety. It is likewise important to integrate the perspectives of resident physicians, policy makers, and other constituencies in designing new policies. However, since its release, discussion of the Institute of Medicine report has been largely confined to the medical education community, led by the Accreditation Council for Graduate Medical Education (ACGME).

To begin gathering these perspectives and developing a plan to implement safer work hours for resident physicians, a conference entitled "Enhancing sleep, supervision and safety: What will it take to implement the Institute of Medicine recommendations?" was held at Harvard Medical School on June 17-18, 2010. This White Paper is a product of a diverse group of 26 representative stakeholders bringing relevant new information and innovative practices to bear on a critical patient safety problem. Given that our conference included experts from across disciplines with diverse perspectives and interests, not every recommendation was endorsed by each invited conference participant. However, every recommendation made here was endorsed by the majority of the group, and many were endorsed unanimously. Conference members participated in the process, reviewed the final product, and provided input before publication. Participants provided their individual perspectives, which do not necessarily represent the formal views of any organization.

In September 2010 the ACGME issued new rules to go into effect on July 1, 2011. Unfortunately, they stop considerably short of the Institute of Medicine's recommendations and those submit your manuscript | www.dovepress.com

Dovepress

http://dx.doi.org//0.2147/NSS.S19649
Nature and Science of Sleep 201 I:3 47-85

47

(C) 201 I Blum et al, publisher and licensee Dove Medical Press Ltd. This is an Open Access article which permits unrestricted noncommercial use, provided the original work is properly cited. 
endorsed by this conference. In particular, the ACGME only applied the limitation of 16 hours to first-year resident physicans. Thus, it is clear that policymakers, hospital administrators, and residency program directors who wish to implement safer health care systems must go far beyond what the ACGME will require. We hope this White Paper will serve as a guide and provide encouragement for that effort.

\section{Resident physician workload and supervision}

By the end of training, a resident physician should be able to practice independently. Yet much of resident physicians' time is dominated by tasks with little educational value. The caseload can be so great that inadequate reflective time is left for learning based on clinical experiences. In addition, supervision is often vaguely defined and discontinuous. Medical malpractice data indicate that resident physicians are frequently named in lawsuits, most often for lack of supervision. The recommendations are:

- The ACGME should adjust resident physicians workload requirements to optimize educational value. Resident physicians as well as faculty should be involved in work redesign that eliminates nonessential and noneducational activity from resident physician duties

- Mechanisms should be developed for identifying in real time when a resident physician's workload is excessive, and processes developed to activate additional providers

- Teamwork should be actively encouraged in delivery of patient care. Historically, much of medical training has focused on individual knowledge, skills, and responsibility. As health care delivery has become more complex, it will be essential to train resident and attending physicians in effective teamwork that emphasizes collective responsibility for patient care and recognizes the signs, both individual and systemic, of a schedule and working conditions that are too demanding to be safe

- Hospitals should embrace the opportunities that resident physician training redesign offers. Hospitals should recognize and act on the potential benefits of work redesign, eg, increased efficiency, reduced costs, improved quality of care, and resident physician and attending job satisfaction

- Attending physicians should supervise all hospital admissions. Resident physicians should directly discuss all admissions with attending physicians. Attending physicians should be both cognizant of and have input into the care patients are to receive upon admission to the hospital

- Inhouse supervision should be required for all critical care services, including emergency rooms, intensive care units, and trauma services. Resident physicians should not be left unsupervised to care for critically ill patients. In settings in which the acuity is high, physicians who have completed residency should provide direct supervision for resident physicians. Supervising physicians should always be physically in the hospital for supervision of resident physicians who care for critically ill patients

- The ACGME should explicitly define "good" supervision by specialty and by year of training. Explicit requirements for intensity and level of training for supervision of specific clinical scenarios should be provided

- Centers for Medicare and Medicaid Services (CMS) should use graduate medical education funding to provide incentives to programs with proven, effective levels of supervision. Although this action would require federal legislation, reimbursement rules would help to ensure that hospitals pay attention to the importance of good supervision and require it from their training programs

\section{Resident physician work hours}

Although the IOM "Sleep, supervision and safety" report provides a comprehensive review and discussion of all aspects of graduate medical education training, the report's focal point is its recommendations regarding the hours that resident physicians are currently required to work. A considerable body of scientific evidence, much of it cited by the Institute of Medicine report, describes deteriorating performance in fatigued humans, as well as specific studies on resident physician fatigue and preventable medical errors.

The question before this conference was what work redesign and cultural changes are needed to reform work hours as recommended by the Institute of Medicine's evidence-based report? Extensive scientific data demonstrate that shifts exceeding 12-16 hours without sleep are unsafe. Several principles should be followed in efforts to reduce consecutive hours below this level and achieve safer work schedules. The recommendations are:

- Limit resident physician work hours to 12-16 hour maximum shifts

- A minimum of 10 hours off duty should be scheduled between shifts

- Resident physician input into work redesign should be actively solicited

- Schedules should be designed that adhere to principles of sleep and circadian science; this includes careful consideration of the effects of multiple consecutive night shifts, and provision of adequate time off after night work, as specified in the IOM report

- Resident physicians should not be scheduled up to the maximum permissible limits; emergencies frequently occur that require resident physicians to stay longer than their scheduled shifts, and this should be anticipated in scheduling resident physicians' work shifts

- Hospitals should anticipate the need for iterative improvement as new schedules are initiated; be prepared to learn from the initial phase-in, and change the plan as needed 
- As resident physician work hours are redesigned, attending physicians should also be considered; a potential consequence of resident physician work hour reduction and increased supervisory requirements may be an increase in work for attending physicians; this should be carefully monitored, and adjustments to attending physician work schedules made as needed to prevent unsafe work hours or working conditions for this group

- "Home call" should be brought under the overall limits of working hours; work load and hours should be monitored in each residency program to ensure that resident physicians and fellows on home call are getting sufficient sleep

- Medicare funding for graduate medical education in each hospital should be linked with adherence to the Institute of Medicine limits on resident physician work hours

\section{Moonlighting by resident physicians}

The Institute of Medicine report recommended including external as well as internal moonlighting in working hour limits. The recommendation is:

- All moonlighting work hours should be included in the ACGME working hour limits and actively monitored. Hospitals should formalize a moonlighting policy and establish systems for actively monitoring resident physician moonlighting

\section{Safety of resident physicians}

The "Sleep, supervision and safety" report also addresses fatigue-related harm done to resident physicians themselves. The report focuses on two main sources of physical injury to resident physicians impaired by fatigue, ie, needle-stick exposure to blood-borne pathogens and motor vehicle crashes. Providing safe transportation home for resident physicians is a logistical and financial challenge for hospitals. Educating physicians at all levels on the dangers of fatigue is clearly required to change driving behavior so that safe hospital-funded transport home is used effectively.

- Fatigue-related injury prevention (including not driving while drowsy) should be taught in medical school and during residency, and reinforced with attending physicians; hospitals and residency programs must be informed that resident physicians' ability to judge their own level of impairment is impaired when they are sleep deprived; hence, leaving decisions about the capacity to drive to impaired resident physicians is not recommended

- Hospitals should provide transportation to all resident physicians who report feeling too tired to drive safely; in addition, although consecutive work should not exceed 16 hours, hospitals should provide transportation for all resident physicians who, because of unforeseen reasons or emergencies, work for longer than consecutive 24 hours; transportation under these circumstances should be automatically provided to house staff, and should not rely on self-identification or request

\section{Training in effective handovers and quality improvement}

Handover practice for resident physicians, attendings, and other health care providers has long been identified as a weak link in patient safety throughout health care settings. Policies to improve handovers of care must be tailored to fit the appropriate clinical scenario, recognizing that information overload can also be a problem. At the heart of improving handovers is the organizational effort to improve quality, an effort in which resident physicians have typically been insufficiently engaged. The recommendations are:

- Hospitals should train attending and resident physicians in effective handovers of care

- Hospitals should create uniform processes for handovers that are tailored to meet each clinical setting; all handovers should be done verbally and face-to-face, but should also utilize written tools

- When possible, hospitals should integrate hand-over tools into their electronic medical records (EMR) systems; these systems should be standardized to the extent possible across residency programs in a hospital, but may be tailored to the needs of specific programs and services; federal government should help subsidize adoption of electronic medical records by hospitals to improve signout

- When feasible, handovers should be a team effort including nurses, patients, and families

- Hospitals should include residents in their quality improvement and patient safety efforts; the ACGME should specify in their core competency requirements that resident physicians work on quality improvement projects; likewise, the Joint Commission should require that resident physicians be included in quality improvement and patient safety programs at teaching hospitals; hospital administrators and residency program directors should create opportunities for resident physicians to become involved in ongoing quality improvement projects and root cause analysis teams; feedback on successful quality improvement interventions should be shared with resident physicians and broadly disseminated

- Quality improvement/patient safety concepts should be integral to the medical school curriculum; medical school deans should elevate the topics of patient safety, quality improvement, and teamwork; these concepts should be integrated throughout the medical school curriculum and reinforced throughout residency; mastery of these concepts by medical students should be tested on the United States Medical Licensing Examination (USMLE) steps 
- Federal government should support involvement of resident physicians in quality improvement efforts; initiatives to improve quality by including resident physicians in quality improvement projects should be financially supported by the Department of Health and Human Services

\section{Monitoring and oversight of the ACGME}

While the ACGME is a key stakeholder in residency training, external voices are essential to ensure that public interests are heard in the development and monitoring of standards. Consequently, the Institute of Medicine report recommended external oversight and monitoring through the Joint Commission and Centers for Medicare and Medicaid Services (CMS). The recommendations are:

- Make comprehensive fatigue management a Joint Commission National Patient Safety Goal; fatigue is a safety concern not only for resident physicians, but also for nurses, attending physicians, and other health care workers; the Joint Commission should seek to ensure that all health care workers, not just resident physicians, are working as safely as possible

- Federal government, including the Centers for Medicare and Medicaid Services and the Agency for Healthcare Research and Quality, should encourage development of comprehensive fatigue management programs which all health systems would eventually be required to implement

- Make ACGME compliance with working hours a "condition of participation" for reimbursement of direct and indirect graduate medical education costs; financial incentives will greatly increase the adoption of and compliance with ACGME standards

\section{Future financial support for implementation}

The Institute of Medicine's report estimates that \$1.7 billion (in 2008 dollars) would be needed to implement its recommendations. Twentyfive percent of that amount (\$376 million) will be required just to bring hospitals into compliance with the existing 2003 ACGME rules. Downstream savings to the health care system could potentially result from safer care, but these benefits typically do not accrue to hospitals and residency programs, who have been asked historically to bear the burden of residency reform costs. The recommendations are:

- The Institute of Medicine should convene a panel of stakeholders, including private and public funders of health care and graduate medical education, to lay down the concrete steps necessary to identify and allocate the resources needed to implement the recommendations contained in the IOM "Resident duty hours: Enhancing sleep, supervision and safety" report. Conference participants suggested several approaches to engage public and private support for this initiative

- Efforts to find additional funding to implement the Institute of Medicine recommendations should focus more broadly on patient safety and health care delivery reform; policy efforts focused narrowly upon resident physician work hours are less likely to succeed than broad patient safety initiatives that include residency redesign as a key component

- Hospitals should view the Institute of Medicine recommendations as an opportunity to begin resident physician work redesign projects as the core of a business model that embraces safety and ultimately saves resources

- Both the Secretary of Health and Human Services and the Director of the Centers for Medicare and Medicaid Services should take the Institute of Medicine recommendations into consideration when promulgating rules for innovation grants

- The National Health Care Workforce Commission should consider the Institute of Medicine recommendations when analyzing the nation's physician workforce needs

\section{Recommendations for future research}

Conference participants concurred that convening the stakeholders and agreeing on a research agenda was key. Some observed that some sectors within the medical education community have been reluctant to act on the data. Several logical funders for future research were identified. But above all agencies, Centers for Medicare and Medicaid Services is the only stakeholder that funds graduate medical education upstream and will reap savings downstream if preventable medical errors are reduced as a result of reform of resident physician work hours.

Keywords: resident, hospital, working hours, safety

\section{Preface}

In its landmark 1999 report "To Err is Human", the Institute of Medicine estimated on the basis of two statewide studies ${ }^{1-3}$ that up to 98,000 patients die each year in the US due to medical error. ${ }^{4}$ Since that time, considerable efforts have been made to understand the causes and consequences of these errors, and to implement interventions to prevent or intercept them. Nevertheless, errors appear to be as common today as they were a decade ago. In November 2010, the US Department of Health and Human Service's Office of the Inspector General estimated that up to 180,000 patients per year may die as a result of medical care, ${ }^{5}$ an extrapolation that would make harm due to medical care the third leading cause of death nationwide. ${ }^{6}$ Nearly half of these incidents 
were preventable, ie, due to error. In the same month, the North Carolina Patient Safety Study reported the results of a 10-center, six-year study that found no reduction over time in the baseline rate ( 25 harms per 100 admissions) due to medical care in North Carolina. ${ }^{7,8}$

While there are numerous reasons that errors and injuries due to medical care remain so prevalent, the traditional long working hours of providers, particularly resident physicians, appear to be an important root cause. The Harvard Work Hours, Health, and Safety Group found that interns working extended shifts reported making more medical errors (including those that harm or kill patients), ${ }^{9}$ had a $60 \%$ increased odds of suffering an occupational injury, ${ }^{10}$ and have twice the odds of suffering motor vehicle crashes on the drive home from work. ${ }^{11}$ Furthermore, in a randomized controlled trial, serious medical errors were found to be $36 \%$ more common on a traditional schedule with frequent extended shifts than on an intervention schedule that eliminated scheduled shifts longer than 16 consecutive hours. ${ }^{12,13}$ Subsequent studies have largely substantiated these findings. A systematic review of interventions that reduced or eliminated shifts over 16 hours found that $64 \%$ resulted in improved safety or quality; no intervention led to worse quality or safety. ${ }^{14}$ Similarly, a systematic review of the relationship between extended shifts and resident physician and patient safety found that outcomes were improved by shorter resident physician work shifts in $74 \%$ of studies; only $6 \%$ of the studies found any outcome to be worse with shorter shifts. ${ }^{15}$

In light of these emerging data and public concern over resident physician working hours, ${ }^{16}$ Congress and the Agency for Healthcare Research and Quality asked the Institute of Medicine to convene a committee to review all data on resident physician working hours and safety. ${ }^{17,18}$ After a year-long comprehensive study, the committee published a report in 2009, concluding that "the scientific evidence base establishes that human performance begins to deteriorate after 16 hours of wakefulness", and called for the elimination of all resident physician shifts exceeding 16 hours without sleep. In addition, they called for numerous improvements in the organization and supervision of residency training, as well as external oversight by the Accreditation Council for Graduate Medical Education (ACGME), the professional body that has historically overseen residency programs.

The recommendations of the Institute of Medicine have profound implications for patients, residency programs, and the health care system. The conclusion that resident physicians' traditional 24-hour work shifts are unsafe has created an upheaval in academic medicine, but one with the potential to yield a safer health care system. However, in order to realize this potential, the Institute of Medicine's report needs to move from being merely a list of recommendations to being a well coordinated series of concrete changes in health care delivery and regulation.

To address this need, a diverse group of stakeholders was invited to attend a conference at Harvard Medical School in June 2010, at which the recommendations of the Institute of Medicine committee were discussed. From this discussion, we produced this White Paper which outlines the group's recommendations regarding how to move forward.

In response to the Institute of Medicine report, the ACGME in September 2010 issued new standards to come into effect on July 1, 2011. Unfortunately, the new rules stop considerably short of the Institute of Medicine's recommendations and those endorsed by this conference. In particular, the ACGME only applied the limitation of 16 consecutive work hours to first-year resident physicians and reduced the minimum time off between shifts from 10 to 8 hours. Policy makers, hospital administrators, and residency program directors who wish to implement safer health care systems must go far beyond what the ACGME will require. This White Paper should serve as a guide for that effort. We hope the exciting examples of programs that have been redesigned to provide a better educational experience within the necessary restrictions of working hours will encourage others to do likewise. The safety of our patients and our trainees requires nothing less. We believe that it is only through fundamental redesign of systems, including especially the redesign of residency care systems, that we will achieve the potential of the patient safety movement to reduce errors substantially and save lives.

Christopher P. Landrigan, MD, MPH and

Lucian Leape, $M D$

Conference Moderators

\section{Introduction}

The Institute of Medicine's "Resident duty hours: Enhancing sleep, supervision and safety" 18 is arguably the most comprehensive examination of the training of physicians since the publication of the Flexner Report 100 years ago. Formed at the behest of Congress, the Institute of Medicine's panel of experts was chaired by Dr Michael Johns, an otolaryngology surgeon and chancellor of Emory University. Its 17 members included physicians and nurse educators, sleep scientists, patient safety and organizational development experts, a consumer, and a resident physician. 
The group was directed to examine the scientific evidence linking acute and chronic sleep deprivation among resident physicians with clinical performance deficits leading to medical error. ${ }^{18}$ Twelve months, six days of public hearings, and countless discussions and drafts later, the committee produced a document which encompassed far more than reform of the hours that resident physicians spend in the hospital.

The report recommended new limits on resident physician work hours and workload, increased supervision, a heightened focus on resident physician safety, training in structured handovers and quality improvement, more rigorous external oversight of work hours and other aspects of residency training, and identification of expanded funding sources necessary to implement the recommended reforms successfully. The recommendations were based on the committee's belief that:

- "There is enough evidence from studies of resident physicians and additional scientific literature on human performance and the need for sleep to recommend changes to resident physician training and duty hours aimed at promoting safer working conditions for resident physicians and patients by reducing resident physician fatigue"

- "Providing safe patient care during residency is a matter not just of hours at work, but also of the amount of effective supervision, sleep obtained, and a balanced workload"18

In the 18 months following its release, the Institute of Medicine report was discussed extensively by the ACGME, the organization that oversees the training of physicians in the US. The ACGME formed a Duty Hours Task Force made up of board of trustee members and other medical educators. ${ }^{19}$ The group began work soon after the Institute of Medicine report was published, a date coinciding with the ACGME's promised five-year review of its 2003 Duty Hour Standards. The task force worked for 18 months. Multiple experts were invited to present before the group, and three additional research studies were commissioned. ${ }^{20-22}$ The prevailing sentiment, captured effectively in an extensive collection of testimonies provided at the June 2009 ACGME Congress on Duty Hours, was that many of the Institute of Medicine's recommendations (and specifically those focusing on reduction of duty hours) should not be implemented.

ACGME president and chief executive officer, Dr Thomas Nasca, addressed the Harvard conference participants on June 17, 2010. He estimated that resident physicians (approximately 109,500 in 2010) represented about one quarter of all hospital-based physicians in the US. Taxpayers, through their contributions to the Medicare system, fund graduate medical education, at a cost of over $\$ 9$ billion in $2009 .{ }^{23}$

Given the public's investment in physician training and its expectation of receiving safe, high-quality care in the nation's 1100-plus teaching hospitals, ${ }^{24}$ the Institute of Medicine report deserves broad and deep examination, and should involve not only input from the graduate medical education community, but from patients, resident physicians, policy makers, and the many other constituencies potentially affected by its far-reaching recommendations.

To that end, a conference entitled "Enhancing sleep, supervision and safety: What will it take to implement the Institute of Medicine recommendations?" was held at Harvard Medical School on June 17-18, 2010. Twenty-six stakeholders participated in the invitation-only roundtable discussion. They included quality improvement experts, medical educators and hospital administrators, consumers, regulators, sleep scientists, policy makers, a resident physician, and a medical student (see Appendix D for biographic information on participants). The group also included two members of the Institute of Medicine committee that produced the "Sleep, supervision and safety" report.

The two-day conference, moderated by Drs Christopher P Landrigan and Lucian Leape, was structured around the 10 major recommendations made by the Institute of Medicine. Each recommendation was introduced and discussed by an initial presenter as well as at least two additional respondents, followed by informal discussion. This format provided an opportunity for experts and a diverse group of stakeholders to present, discuss, and debate implementation strategies, including opportunities, obstacles, and concrete steps to address this important patient safety issue. Not every recommendation was endorsed by each invited conference participant. However, every recommendation made here was endorsed by the majority of this diverse group of experts and many were endorsed unanimously.

The goals of the conference were to produce and disseminate widely a White Paper that would:

- Broaden exposure to the Institute of Medicine report beyond the medical community

- Share the collective wisdom of experts in their fields and diverse stakeholders about how best to implement the 10 Institute of Medicine recommendations, ie, best practices for medical education innovators 
- Provide an impetus for change that will help pave the way towards creating a safer and more effective system for training the nation's physicians

In September 2010 the ACGME issued new rules to go into effect on July 1, 2011, but unfortunately these stop considerably short of the Institute of Medicine's recommendations and those endorsed by this conference. In particular, the ACGME only applied the limitation of 16 hours to firstyear resident physicians and reduced the minimum time off between shifts from 10 to 8 hours. In addition, other important IOM recommendations were disregarded. Hospitals, medical educators and policy makers committed to implementing safer systems of care must go further. This White Paper should serve as encouragement that further change is both possible and desirable.

\section{Resident physician workload and supervision}

"To improve the quality of care delivered to current and future patients, and to meet long term educational objectives, the committee recommends improvements to the content of residents' work, a patient workload and intensity appropriate to learning, and more frequent consultations between residents and their supervisors."

Resident Duty Hours: Enhancing Sleep, Supervision and Safety (Medicine 2009, p. 19)

"Extreme time demands dilute the relationships between residents and faculty."

Joel Katz, MD, Program Director, Internal Medicine

Brigham and Women's Hospital, Boston, MA

Harvard IOM Conference, June 17, 2010

Successful medical training combines formal education and experiential learning under the supervision of experienced physicians. By the end of training, a resident physician should be able to practice independently. Yet too often, a resident physician's time is dominated by tasks with little educational value and a caseload so great that inadequate reflective time is left for learning based on clinical experience. In addition, supervision is often vaguely defined, discontinuous, and poorly monitored.

The Institute of Medicine's "Sleep, supervision and safety" report describes in detail the underlying reasons for this deterioration, ie, a system of reimbursement that results in patients being sicker upon admission (and discharge) and exerts financial pressure to reduce length of hospital stay. More clinical service is expected both of resident physicians and attending physicians in shorter periods of time.
These economic pressures, which started to be recognized by the late $1980 \mathrm{~s},{ }^{25}$ were further exacerbated after 2003 when the ACGME enacted its first limits on working hours. Many teaching hospitals met this unfunded mandate by simply demanding more work from physicians-in-training and attending physicians alike.

Today the responsibilities of attending physicians "on service" are often so stressful and demanding that the typical schedule has been reduced from one month to two weeks or less. This discontinuity further dilutes the resident-attending physician relationship. Too much work and too little supervision may result in near-misses and preventable medical errors. In addition, patients overwhelmingly disapprove of resident physician working shifts that exceed 16 hours in duration, and believe that increasing their supervision could improve care. ${ }^{16}$

How can resident physicians receive the appropriate level of patient exposure and clinical training while ensuring patient safety? How is high-quality supervision defined, funded, monitored, and enforced? Conference participants considered these questions when reviewing the Institute of Medicine's recommendations regarding resident physician workload and supervision (see Appendix B for a compilation of the 10 Institute of Medicine recommendations). Addressing excessive hospital workload and inadequate supervision could provide safer patient care and improve the training environment for resident physicians, as well as resident physician and attending satisfaction. ${ }^{27}$ Such changes could also potentially result in financial savings sufficient to pay for the additional cost of a care model in which resident physicians cover fewer patients and have more supervision.

\section{Recommendations for resident physician workload}

- The ACGME should adjust resident workload requirements to optimize educational value; resident physicians as well as faculty should be involved in work redesign that eliminates nonessential and noneducational activity from resident physician duties

- Mechanisms should be developed for identifying in real time when a resident physician's workload is excessive, and processes developed to activate additional providers

- Teamwork should be actively encouraged in delivery of patient care; historically, much medical training has focused on individual knowledge, skills, and responsibility; health care delivery has become more complex, so it will be essential to train resident and attending physicians 
in effective teamwork that emphasizes collective responsibility for patient care and recognizes the signs, both individual and systemic, of a schedule and other working conditions that are too demanding to be safe

- Hospitals should embrace the opportunities that resident physician training redesign offers; hospitals should recognize and act on the potential benefits of work redesign, eg, increased efficiency, reduced costs, improved quality of care, and resident and attending job satisfaction

Lack of supervision has consequences. Resident physicians are held to the standard of a "reasonable provider" and are frequently named in malpractice lawsuits. Their errors result in malpractice payouts by insurers. The Malpractice Insurer's Medical Error Prevention Study ${ }^{26}$ reviewed more than 1400 closed malpractice cases from five different insurers in 1984-2004, of which 889 were identified whereby both error and injury to a patient occurred. Of those, $240(27 \%)$ involved trainees whose role in the error was judged to be at least moderately important. In $82 \%$ of the cases involving lack of supervision (106 of 129), failure of attending physicians to supervise was at issue.

The Controlled Risk Insurance Company (CRICO) insures more than 11,400 physicians, including 3700 resident physicians/fellows at 25 hospitals affiliated with the Harvard Medical School in the Boston area. According to Controlled Risk Insurance Company data, $15 \%-20 \%$ of the physicians named as defendants in historical malpractice cases (about 40 per year) were resident physicians.

A review of unpublished closed case data for the Controlled Risk Insurance Company between January 1, 2005 and May 31, 2010, revealed that:

- One or more residents were involved as defendants in 154 cases, and $20 \%$ of those cases involved just a resident physician

- Sixty percent (99 cases) were considered of high severity, and $15 \%$ higher in injury severity when note was taken of resident physician supervision and working hours

- Disposition of cases involving resident physicians dropped/denied/dismissed in 39\%, a defense verdict given in $24 \%$, a plaintiff verdict in $1 \%$, and settled in $36 \%$ of cases

- Top major allegations against resident physicians that resulted in payouts involved surgical treatment (52 cases, \$14.6 million), diagnosis-related issues (34 cases, \$18.1 million), medical treatment (27 cases, \$11.07 million), obstetric-related treatment (18 cases, $\$ 9.7$ million), medication-related issues (eight cases, \$2.1 million), and anesthesia-related treatment (seven cases, $\$ 1.9$ million)
- Top contributing factors (a case may have multiple factors identified) were supervision (29\%), communication among providers regarding patient's condition (26\%), lack of/ inadequate assessment and/or failure to note clinical information (16\%), and possible technical problems (16\%)

High-quality supervision of resident physicians must be fostered in all disciplines of medicine. "Supervision in the operating room (and other procedure-based training) is both different and similar to supervision in the cognitive fields of medicine", noted Dr James Whiting, director of surgical education at Maine Medical Center. "Doing an operation with a trainee is akin to dancing with a partner, who starts off dancing on your feet and then - as a chief resident - can do a complex dance and you say - go ahead and lead. Yet on the issue of independence, surgery isn't different. At some point we want them to be able to 'do this on their own'. How do you assess competency and give them independence while maintaining supervision? How are they going to respond in a crisis?"

But how do we get from the status quo to a training environment with high-quality supervision? Restructuring resident physician team structure, workload, and supervision can improve education, satisfaction, and quality of care. This hypothesis was tested in the internal medicine residency program at the Brigham and Women's Hospital. ${ }^{27}$ The intervention group comprised a population of 15 intensive care patients (average 4-5 patients per intern), a team consisting of two resident physicians, two interns, two seniors and coattendings (one hospitalist and one primary care provider or medical specialist) who had extensive contact with trainees and patients, and a reduced frequency of overnight call. The control group, ie, the general medicine service, had a maximum ACGME census (average 6-8 patients per intern), and a team of one resident, two interns, and multiple care attendings with a variable degree of contact with trainees and patients, and a traditional overnight call schedule. Trainees worked an average of about 62 hours per week. The study found that, as compared with the control general medicine service, on the intensive care intervention service:

- Resident physicians spent more of their time in educational activities (29\% versus $7 \%$ )

- Resident physicians were more satisfied (78\% versus 55\%)

- Attending physicians were more satisfied, in that $70.7 \%$ felt the model was closest to their ideal teaching experience, and 90.2\% approved of the dual attendingphysician model

- Patient satisfaction did not differ significantly between teams 
- Length of stay was shorter (4.10 versus 4.61 days); the cost of implementing the intensive care intervention was estimated at $\$ 500,000$; this was counterbalanced by decreased intensive care costs of $\$ 600,000$ due to shortened length of stay in the intensive care unit

The investigators concluded the importance of:

- Strengthening connections between formal and experiential learning

- Increasing opportunities for reflection to improve resident physicians' educational experiences; this needs to be balanced with case volume

- Increasing contact with a devoted teaching faculty enhances resident physicians' experience

- Fully engaging supervisors (senior resident physicians and faculty) in the direct care process without taking decision-making power away from the intern through;

- clear role definitions

- shared responsibility and accountability (requires longitudinal relationship)

- integrated team building of trainee, supervisor and patient (eg, bedside rounds)

- bidirectional feedback (eg, performance, teaching and documentation)

- faculty compensation

- faculty development

\section{Conference recommendations for supervision}

- Attending physicians should supervise all hospital admissions; resident physicians should directly discuss all admissions with attending physicians; attending physicians should be both cognizant and have input into the care patients are to receive upon admission to the hospital

- Inhouse supervision should be required for all critical care services, including emergency rooms, all intensive care units, and trauma services; resident physicians should not be left unsupervised to care for critically ill patients; in high acuity settings, physicians who have graduated from residency should provide direct supervision of resident physicians; supervising physicians should always be physically in the hospital to provide supervision of critically ill patients

- The ACGME should explicitly define "good" supervision by specialty and by year of training; explicit requirements for intensity and level of training for supervision of specific clinical scenarios should be provided

- Centers for Medicare and Medicaid Services should use graduate medical education funding to provide incentives for programs with proven effective levels of supervision. Although implementation of this recommendation may require federal legislation, reimbursement rules would help to ensure that hospitals pay attention to the importance of good supervision and require it from their training programs.

\section{Resident physician working hours}

"The Committee reviewed the scientific literature on sleep and human performance as well as evidence that continues to emerge concerning the benefits to patient safety, resident learning, and overall resident work life of well-structured limits to resident duty hours. The evidence was sufficient to recommend action now."

\section{Resident Duty Hours: Enhancing Sleep, Supervision} and Safety (Medicine 2009, p. 7)

"What work redesign and culture changes are needed to reduce work hours to the IOM-recommended levels?"

Charles A. Czeisler, $M D, P h D$,

Chief, Division of Sleep Medicine, Brigham

and Women's Hospital

Although the "Sleep, supervision and safety" report provides a comprehensive review and discussion of all aspects of graduate medical education training, the report's main focus is its recommendation for changes to the hours that resident physicians are currently required to work. Indeed, it was the quest to understand the link between resident physician work hours and patient safety that caused a subcommittee of the Oversight and Investigations of the House Committee on Energy and Commerce to request that the Department of Health and Human Services sponsor a study by the Institute of Medicine.

The Institute of Medicine recommended a significant departure from the current limits placed on resident physician work by the ACGME, which currently allow shifts of 30 consecutive hours ( 24 plus six more hours for continuity of care/transition of patient information). The Institute of Medicine concluded that no resident physician should work for more than 16 consecutive hours without sleep. If residency programs wanted to continue the practice of 30-hour shifts, the Institute of Medicine recommended that a protected five-hour sleep period occur between the hours of $10 \mathrm{pm}$ and $8 \mathrm{am}$, and that no new patient care duties be allowed after 16 hours.

A considerable body of scientific evidence (much of it cited by the Institute of Medicine report) describes deteriorating performance in fatigued humans, as well as specific 
studies on resident physician fatigue and preventable medical errors. A meta-analysis of 60 studies on the effect of sleep deprivation found, on average, after 24-30 hours of wakefulness, that "for clinical performance physicians performed at the 7 th percentile of the comparison group". ${ }^{28}$

Tired resident physicians make errors. In one study, one in every five interns reported making a fatigue-related mistake that injured a patient (a 700\% increase when interns worked greater than 24 hours) and one in every 20 interns admitted to a fatigue-related mistake that resulted in the death of a patient (a 300\% increase in months that interns worked five or more 24-hour shifts). ${ }^{9}$

Since the 2009 publication of the Institute of Medicine report, the peer-reviewed evidence has continued to describe preventable medical errors due to physician fatigue. There were $171 \%$ more surgical complications (eg, organ damage, hemorrhage) that occurred in day-time operations when the attending surgeon had had fewer than six hours of sleep opportunity after performing a nighttime procedure. ${ }^{29}$

Reducing the marathon shifts that resident physicians now work poses both logistic and economic challenges. Unfortunately these challenges are often not addressed, because the ACGME's core constituencies and multiple specialty societies hold fast to the belief that long hours are required of resident physicians in order to ensure competency and instill professionalism. ${ }^{30}$

The question before this conference was what work redesign and culture changes are needed to reform work hours as recommended by the Institute of Medicine's evidencebased report?

Work redesign and culture change can (and are) being done with positive results. One study ${ }^{14}$ systematically reviewed the effects of reducing or eliminating shifts greater than 16 hours on patient safety and quality of care. Of the 11 programs described in previously published reports, seven reported significant improvement in patient safety and quality of care and four reported no change.

The conference featured case study experiences of innovative residency presented by program directors in three different specialties in the US, including internal medicine, general surgery, and obstetrics and gynecology. Also presented was a best practice entitled "Hospital at Night" from the UK, where implementation of the European Working Time Directive reduced work hours for trainees from 72 hours per week to 56 hours in 2004, and to 48 hours in 2009 (see Appendix A). What "lessons learned" did these pioneers impart?
- Change is difficult and will always be resisted, such that if program directors wait until there is attending/ resident physician consensus for change, it will never happen

- Program leadership is needed to redesign schedules to reduce hours; there will be inevitable early complaints, but the concerns diminish when resident physicians experience the benefits of the change

- Involve resident physicians in the work redesign; they are able to identify where the schedule is dysfunctional and suggest changes

- Continuity of care is enhanced, with fewer handovers when day and night float team care for the same patients

- Tailor redesign to the program, no two programs are the same, so work redesign will differ among programs and within hospitals

- Reform is more successful with buy-in from hospital administration; this should be framed in terms of reform leading to streamlined discharges, reduced length of stay, and improved resident physician/faculty job satisfaction; additional upfront costs can be recouped

- Use technology (eg, simulation laboratories) to boost the learning curve

- Where redesign involves additional attending physician responsibility and time, additional compensation may also be required

- Schedule shifts with a buffer time period; work hours should be scheduled to allow resident physicians to stay longer to fulfill patient responsibilities and pursue educational opportunities, eg, a schedule should be made to allow a 13-14-hour shift to extend to 16 hours (see Tables 1, 2 and 3)

\section{Home call: a problem still waiting to be addressed}

Since the ACGME instituted its 2003 working hour limits, more residency programs, particularly in the surgical subspecialties, have moved some of their inhouse call to home call. The incentive for such programs is that the ACGME counts home call towards the 80-hour/week limit only when a resident physician or fellow has to come into the hospital to care for a patient. It is common sense that, like all medical staff, resident physicians prefer to work from home. Home call can provide good training for post-residency life an attending physicians. But when the workload is too great and/or the pages trivial, home call can become a safety problem whereby home call can worsen the accumulation of chronic sleep deprivation because, unlike hospital call where resident physicians only 
Table I Innovation case study - internal medicine

Summa Health System (affiliate of North East Ohio University College of Medicine), Akron, OH.

Program Director - David B. Sweet, MD (sweetd@summa-health.org).

\begin{tabular}{|c|c|}
\hline 563 Bed Hospital: & 100-120 Medicine residency beds \\
\hline Resident Physicians: & $\begin{array}{l}\text { 68-45 IM Categorical + } 6 \text { IM Prelim PGY I + } 10 \text { Trans Yr Prelim PGY I + } 7 \text { FTE } \\
\text { Rotators. } \\
\text { [IM = Internal Medicine; PGY = Postgraduate Year; FTE = full time employee }]\end{array}$ \\
\hline Schedule: & $\begin{array}{l}<2004-\text { traditional } 24+6 \text { call } \\
>2006-80 \% \text { I2-13 hour calls / } 20 \% \text { I } 6 \text { hour calls with Saturday cross-coverage to } \\
\text { preserve I free "golden weekend" per month. }\end{array}$ \\
\hline Impetus for Change: & $\begin{array}{l}\text { Consistently over hours limits; literature supported reduced hours; support from } \\
\text { ACGME Educational Innovation Project. }\end{array}$ \\
\hline Obstacles to Implementation: & Inertia (fear of change / it can't be done). \\
\hline Cost: & $\begin{array}{l}\text { No hiring of additional personnel; } 3 \text { elective months lost in } 3 \mathrm{yrs} \text {; re-schedule continuity } \\
\text { clinic on post-admitting days. }\end{array}$ \\
\hline Secrets to Success: & $\begin{array}{l}\text { Involve resident physicians and study work flow; minimize change for PGY 3s; create } \\
\text { schedule to allow a buffer time to finish care tasks; expect to revise the schedule in } \\
\text { the second year; use quality (education and continuity of care) metrics; promote more } \\
\text { organized handovers. }\end{array}$ \\
\hline Outcome: & $\begin{array}{l}\text { Found that rested resident physicians read more, attended more didactic sessions; } 7 \text { of } \\
16 \text { June } 2010 \text { graduates presented research at national or international meetings. }\end{array}$ \\
\hline
\end{tabular}

Table 2 Innovation case study - Ob-Gyn

Santa Clara Valley Medical Center (affiliated with Stanford University School of Medicine).

Assoc. Program Director - Jennifer Domingo, MD (Jennifer.domingo@hhs.sccgov.org).

\section{Bed Hospital:}

Resident Physicians:

Problems with Previous Current

Call System:

Changed to Night Float System July I, 20 I0. NEW Schedule Establishes:

\section{Advantages to New Schedule}

Postscript with busy OB service ( $\sim 5000$ deliveries)

20-22 (I5 OB, 3-4/mo FP, 2-3/yr FP Ob Fellows and I Trans/mo)

- Lack of proper coverage in day duties when post-call resident physicians had to go home; gaps in coverage on Labor \& Delivery/OR services

- Coverage problems exacerbated when Resident physician on team was also on vacation

- Loss of continuity of care with service patients and lack of accountability

- Resident physicians too exhausted to learn on education mornings

- Elimination of the $24 \mathrm{hr}$ shift for ALL residents. Work hour shifts range from 13-16 hrs which includes patient hand-offs

- All residents get I day off/7days NOT averaged and one 48 -hr period/4 weeks NOT averaged

- Resident work hours do NOT exceed 80 hrs/week NOT averaged over 4 weeks

- 14 block rotations (including I vacation block - resident physicians can switch out 2 of 4 weeks with other resident physicians)

- Night float system will allow day and night teams to split into two 12 hour shifts with time for sign-out

- Resident physicians played an active role in development of work redesign

- Consistent full day teams with improved continuity and accountability for patient care

- Same teams sign out to each other five nights per week

- Improved education experience with resident physicians able to attend all clinics/operate on OR days because not post-call; able to follow through on care of complicated patients/pre-op and post-op care; alert and awake for educational conferences

- Resident physicians make their own schedules - accountable to themselves

- Dr. Domingo reports that in the seven months since implementation of the new resident schedule on July I, 2010, more and more Ob-Gyn attending physicians are now choosing to split their 24 hour weekend call shifts into 12 hour shifts. On week days, attendings work 16 hour shifts, but many are also now switching to 12 hour shifts there as well. "It's interesting," says Dr. Domingo, "but I think many of us are starting to appreciate the effects of fatigue on patient safety and balance this with overall job satisfaction." 
Table 3 Innovation case study in surgery

Maine Medical Center (affiliate of Tufts School of Medicine), Portland, ME.

Program Director - James F. Whiting, MD (whitij@mmc.org).

\section{Bed Hospital}

Resident Physicians:

July 2008:

Phase I - Figure out the problem:

Phase I - Results:

Phase 2:

Phase 3 - Culture change:
20

270 work hour violations (in one month) as I assumed program director position.

Non-compliance in every area; data inaccurate or nonexistent; no one knew the rules and attendings didn't feel there was a problem.

Established administrative compliance policy; all violations looked into; sessions with resident physicians; attending retreat.

Good compliance with work hour recording; learned certain services habitual offenders; systemic violations.

Continuation of oversight and monitoring; tweaks to schedule to eliminate systemic violations; one large service split in two as service was too big to round efficiently. Mock ACGME survey was conducted and mandatory recovery day instituted (if resident physician looks like they would be tracking too many hours they'd go home). Attendings pay more attention to hours (Note: On-call surgical attendings are encouraged not to schedule elective surgery on post-call day).

"Despite a failure to demonstrate any significant detrimental impact of the work hour rules through data, it has recently become fashionable to blame work hour rules for eroding the surgical culture of accountability and ownership. According to this line of thought, work hour rules come with significant unintended consequences: surgical residents are acquiring the mentality of shift workers, no longer assuming the same ownership that we attained through working 100 hour plus weeks. This is not something that can be measured, but we know it is happening nevertheless....

"This kind of thing would be much easier to ignore if it was not so corrosive to the morale of surgical residents and if it did not fly in the face of what I see in the role of surgical program director every day. What is the major number of hours that one must work to learn the lessons of responsibility and accountability anyway?... The 'average' surgeon in the United States works 60 to 70 hours a week, but somehow understands this noble quality of patient ownership whereas today's residents are 'shift workers?'.... Responsibility and ownership will never go out of style, but how those values are manifested is changing. Our residents know that accountability and collaboration are not mutually exclusive.

"I believe that the current generation of surgical residents are better than we were, and work hour restrictions are part of the reason. They are a technologically savvy, cooperative, balanced generation. They are more efficient than we were, more open to new ideas, and just as committed to their patients. They understand the public's uneasiness with our infatuation with endurance as a stand-in for excellence..... It is time to grow up and stop whining. The dinosaurs went extinct and our surgical heritage deserves to evolve."

James F. Whiting Of Puppies and Dinosaurs: Why the 80-Hour Work Week is the Best Thing That Ever Happened in American Surgery Archives of Surgery, Vol. 145 (No. 4), April 2010 work a half-day post call, resident physicians/fellows on home call are expected to work a full post-call day, even if they have been awakened many times during the night to answer pages. Moreover, fellows often take home call in one-week blocks. This work pattern adds to chronic sleep deprivation.

\section{Recommendations on work hours}

- Limit resident physician work hours to 12-16-hour maximum shifts

- A minimum of 10 hours between shifts

- Resident physician input in work redesign should be actively solicited 
- Schedules should be designed that adhere to principles of sleep and circadian science; this includes careful consideration of the effects of multiple consecutive night shifts, and provision of adequate time off after night work

- Resident physicians should not be scheduled up to the maximum permissible limits; emergencies frequently occur that require resident physicians to stay longer than their scheduled shifts, and this should be anticipated in scheduling

- Resident physicians' work shifts

- Hospitals should anticipate the need for iterative improvement as new schedules are initiated; be prepared to learn from the initial phase-in, and change the plan as needed

- As resident physician work hours are redesigned, attending physicians should also be considered. A potential consequence of resident work hour reduction and increased supervisory requirements may be an increase in work for attending physicians. This should be carefully monitored, and adjustments to attending physician work schedules made as needed to prevent unsafe work hours or working conditions for this group

- "Home call" should be brought under the overall limits of work hours. Work load and hours should be monitored in each residency program to ensure that resident physicians and fellows on home call are getting sufficient sleep

- Medicare funding for direct medical education for each hospital should be tied to adherence to the resident physician work hour limits set down by the Institute of Medicine

\section{Moonlighting by resident physicians}

"The Committee concludes that all moonlighting for patient care, whether at the training facility (internal moonlighting) or elsewhere (external moonlighting), should come within the 80-hour weekly limit and that all other duty hour parameters should apply."

Resident Duty Hours: Enhancing Sleep, Supervision and Safety (Medicine 2009, p. 251)

"Residents have an allergic reaction to limiting moonlighting, but if you care about patient safety then you have to care about monitoring moonlighting carefully".

Farbod Raiszadeh, $M D, P h D$

Cardiology Fellow, Montefiore Medical Center, Bronx, NY

President, Committee of Interns and

Residents/SEIU Healthcare

Harvard IOM Conference Presentation, June 17, 2010

The Institute of Medicine report recommended including external as well as internal moonlighting in working hour limits. The report also called on hospitals that permit moonlighting to ensure a process whereby resident physicians would have to apply for permission and be able to evaluate that there was no adverse effect on the resident's performance. The Institute of Medicine reported no recent national assessment of the degree to which resident physicians and fellows moonlight. ${ }^{18}$ Conference discussion revealed that some specialties (eg, surgery) prohibit moonlighting, and that resident physicians who are permitted to moonlight view it as an important way to supplement their income, and as a valuable part of their training experience. Most participants felt that hospitals do a poor job of monitoring external moonlighting by resident physicians.

\section{Recommendations on moonlighting}

- All moonlighting should be included in the ACGME's working hour limits, and actively monitored. Hospitals should formalize a moonlighting policy and establish systems for actively monitoring moonlighting by resident physicians. If moonlighting is found to impair resident physician performance, it should be restricted as needed

\section{Safety of resident physicians}

"As residents acquire needed skills during their educational training, the degree of fatigue and workload they experience places them at risk for workplace injury, driving incidents, decreased physical and mental health, and weakened professional and personal relationships".

Resident Duty Hours: Enhancing Sleep, Supervision and Safety (Medicine 2009, p. 159)

"Of course we have to provide adequate transportation - it's not a matter of finance, it's a matter of priorities, this is what we have to do. But the real question is why are we putting them at risk in the first place?"

David Cohen, $M D$

Executive Vice President for Clinical and Academic

Development,

Maimonides Medical Center, Brooklyn, NY

Patients are not the only victims of punishing schedules (see Table 4). The "Sleep, supervision and safety" report also addressed the harm done to resident physicians themselves. The report focused on two main sources of physical injury to resident physicians impaired by fatigue, ie, needle-stick exposure to blood-borne pathogens and motor vehicle crashes. The report also discussed numerous other personal and professional hazards, including burnout, depression, and the health deficits of likely weight gain. ${ }^{18}$

The Institute of Medicine made the strong recommendation that "sponsoring institutions immediately begin to provide safe transportation options (eg, taxi or public transportation 
Table $4 \mathrm{~A}$ hospital is a dangerous place - especially if you are tired

Wide Range of Hazards

- Infectious agents

- Chemicals and physical agents

- Lifting and repetitive tasks (ergonomic hazards)

Shift Work, Long Hours Impairs Functioning of Many Body Systems

- Impaired immune functioning

Sleep Deprivation Weakens the Healthcare Team Model

- Impaired cognititive flexibility

- Poor risk assessment
- Stress (psychological hazards)

- Workplace violence

- Suboptimal organization of work

- Musculosketal disorders

- Bad mood, personality changes

- Difficulty in personal relationships

Claire C. Caruso PhD, RN, Research Health Scientist National Institute for Occupational Safety and Health Harvard IOM Conference presentation, June I7, 2010 vouchers) for any resident physician who for any reason is too fatigued to drive home safely". ${ }^{18}$ Presumably the committee believed that its recommendation to reduce the number of hours that resident physicians were scheduled to work would address the other serious health consequences of fatigue.

\section{Dangers of needle-stick injuries and motor vehicle crashes}

Percutaneous injury puts resident physicians at risk of acquiring a blood-borne pathogen, eg, hepatitis $\mathrm{C}$ or human immunodeficiency virus. Results of a survey of 2737 interns documented a higher rate of exposure to injury when fatigued. First-year resident physicians reported sustaining more than twice the number of percutaneous injuries at night than during the day (odds ratio 2.04, confidence interval [CI] 1.98-2.11) and sustaining such injuries nearly twice as often while working extended shifts ( 24 hours or longer) compared with working a day shift only (odds ratio 1.61, CI 1.46-1.78). ${ }^{10}$

Similarly, working marathon shifts also increases the risk of motor vehicle crashes, injuring both resident physicians and others. In a national survey of interns, it was found that every extended work shift (more than 24 hours) scheduled in a month increased the monthly risk of a motor vehicle crash by $9.1 \%(95 \%$ CI 3.4-14.7) and increased the monthly risk of a crash during the commute home from work by $16.2 \%$ (95\% CI 7.8-24.7). ${ }^{11}$

Responsibility for resident physician safety in the hospital rests with the employer. On the way to and from a resident physician's home, it is less clear who is legally responsible for the safety of resident physicians. "Dram shop liability" refers to the body of law governing the liability of hospitals in which resident physicians cause death or injury to third parties (those not having a relationship with the hospital) as a result of fatigue-related car crashes and other accidents. Dram shop laws vary across states, but in some states the law may hold hospitals legally accountable for resident physicians' motor vehicle crashes that happen on the way home from an extended-duration shift.
Providing safe transport home for resident physicians is a logistic and financial challenge for hospitals. Conference participants agreed that those supervising resident physicians should dictate when a resident physician is not allowed to drive home if drowsy. Most also agreed that forcing fatigued resident physicians not to drive themselves home was no more a threat to their personal liberty and self-reliance than a man at a bar who is inebriated and for whom the bartender calls a cab. Departing from the Institute of Medicine recommendations, the conference participants decided that after all 24-hour calls, the hospital has an obligation to provide resident physicians with a ride home from the hospital. Public transport was not viewed as a viable solution. "Being comatose on the subway can be dangerous," commented conference participant Dr Farbod Raiszadeh, who described a time on the New York City subway system when he was supposed to get off at 86th Street and ended up 11 stops later on 14 th Street.

Most importantly, providing safe transport home does not address the root cause of the increased risk of a motor vehicle crash, ie, fatigue. Reduce the risk of resident physicians reaching debilitating fatigue a priori, and the problem begins to disappear on its own.

There is still much work to be done on educating both resident and attending physicians about the dangers of fatigue. "This will require a fundamental shift in the medical training culture," said Dr Kavita Patel. "The attitude is 'being able to stay up 48 hours makes me better than someone else'. We need to work towards a place where physicians in a position of authority are willing to say 'I've had enough; I know my limits. Maybe you need to get to know yours."

\section{Recommendations on resident physician safety}

- Fatigue-related injury prevention (including not driving while drowsy) should be taught in medical school and 
residency and reinforced with attending physicians; hospitals and residency programs must be informed that resident physicians' ability to judge their own level of impairment is impaired when they are sleepdeprived; hence, leaving decisions about whether to drive or not to impaired resident physicians is not recommended

- Hospitals should provide transport for all residents who report feeling too tired to drive safely; in addition, although consecutive working hours should not exceed 16 , hospitals should provide transport for all resident physicians who for unforeseen reasons or emergencies work for longer than 24 consecutive hours; transport under this circumstance should be automatically provided to house staff, and should not rely on self-identification or a request

\section{Training in effective handovers and quality improvement}

"System changes are needed in addition to enhanced supervision, workload adjustment and fatigue prevention methods to enhance conditions for resident performance and patient safety. ... A transformation in the medical environment is needed so that a system-wide culture of safety develops and a system of blame is replaced with one of shared responsibility".

Resident Duty Hours: Enhancing Sleep Supervision and Safety (Medicine 2009, p. 263)

"I was blind to the mayhem," described a resident, after spending a week observing all of the disciplines at work on an inpatient unit as part of a quality improvement project. "I never understood how this place works."

As described by Maureen Bisognano,

President and CEO, Institute for

Healthcare Improvement,

Boston, MA

Harvard IOM Conference, June 17, 2010

The IOM "Sleep, supervision and safety" report recommends that resident physicians be trained in effective handover techniques and the science and practice of quality improvement. Resident physicians represent an estimated one out of every four hospital-based physicians, yet including them in hospital quality improvement efforts has been difficult to achieve.

Handover practice for resident physicians, attending physicians, and other health care providers has long been identified as a weak link in patient safety throughout all health care settings. The process by which resident physicians transfer responsibility of care at various transition points poses a potential opportunity to omit or dilute information that could affect patient care. A resident physician's familiarity with a patient is extremely important, but resident physicians cannot remain continuously by the bedside of all their patients. Resident physician fatigue also poses a significant threat to patient safety. ${ }^{12}$

Policies to improve handovers must be tailored to fit the appropriate clinical scenario, recognizing that information overload can also be a problem; beyond the characteristics commonly acknowledged as part of quality handover practice (face-to-face in a quiet space, with minimal interruption, and use of both verbal and written communication tools), conference participants also stressed the need for multidisciplinary rounds at the bedside involving, whenever possible, patients and/or family members.

Electronically printed handovers have been demonstrated to improve resident physician performance and patient outcomes by reducing rates of adverse events and allowing resident physicians more time to spend on direct patient care; ${ }^{31}$ however, electronic reports cannot be seen as a substitute for teaching resident physicians how to exchange quality information, develop good overall communication skills, and recognize the importance of working in teams.

\section{Communication errors and fatigue}

- Root cause analysis case reports from the Veterans Affairs National Center for Patient Safety from 153 medical centers and over six million patients found that approximately $70 \%$ of the root contributing factors in an adverse patient event or near miss are attributed to communication failures, and approximately $30 \%$ of these events are related to fatigue and scheduling

- A Joint Commission review of sentinel events from 1995-2008 yielded similar statistics

- Communication failure related to handoffs is a frequently cited contributing factor in malpractice claims

- Multiple qualitative studies and surveys indicate that resident physicians view ineffective patient handoffs as common causes of adverse events

Edward J. Dunn, $M D, S c D$

Associate Chief, Performance Improvement, Lexington VA

Medical Center, Lexington, $K Y$

Harvard IOM Conference presentation, June 17, 2010 
At the heart of improving handovers is an attempt to improve quality. Quality improvement is the foundation of health services research, and has become a major focus of hospital administrators across the country, with various drivers, including Centers for Medicare and Medicaid Services requirements, the Joint Commission, and the Affordable Care Act. Educating resident physicians about quality improvement has been shown to have a positive effect on patient outcomes, ${ }^{32,33}$ and is increasingly a requirement of medical training and certification, eg, the American Board of Medical Specialties Maintenance of Certification Program and the ACGME core competencies (Practice-Based Learning and Improvement and Systems-Based Practice) which apply to all US physicians in training.

\section{Ferrari and the nature of a good handover}

Highly reliable health care depends upon highly reliable handovers. Health care is now learning lessons from other industries, eg, racing and aviation, on how to improve handovers. Great Ormond Street Hospital for Children in London set out to improve handovers between surgery and intensive care after a serious adverse event occurred when a child was transferred from the operating room to the intensive care unit but the room, staff, and ventilator were not ready. Hospital staff visited Ferrari in Maranello, Italy, to learn from those who have perfected the pit stop, ie, the epitome of perfect handovers and succinct, effective communication about racing crew changeovers. They showed Ferrari a video of a typical patient handover at Great Ormond Street Hospital. The Ferrari staff were appalled, and set out to redesign the process by:

- Training each staff member for a specific task set

- Developing protocols for each member of the team, with resident physicians leading in handover management

- Sequencing the steps

- Using the anesthesiologist as a "lollipop man" to wave the patient into a completely prepared ICU room

As a result, there was a $42 \%$ reduction in average number of technical errors per handover, and information omissions during handovers fell by $49 \%$, with a slightly reduced time to transfer

\section{Maureen Bisognano}

President and CEO, Institute for Healthcare Improvement,

Boston, $M A$

Harvard IOM Conference presentation, June 17, 2010

\section{Recommendations on training in handovers}

- Hospitals should train attending and resident physicians in standardized effective handovers

- Hospitals should create uniform processes for handovers that are tailored to meet each clinical setting. All handovers should be done verbally and face-to-face, but should also utilize written tools

- When possible, hospitals should integrate handover tools into their electronic medical records systems. Electronic medical records systems should be standardized to the extent possible across residency programs in a hospital, but may be tailored to the needs of specific programs and services. The federal government should help subsidize hospital adoption of electronic medical records to improve signout

- When feasible, handovers should include nurses, patients, and families

Involving resident physicians in quality improvement projects has the potential to demonstrate, at a critical time in medical training, that a focus on quality can improve care. However, moving from this abstract notion to concrete implementation is not always easily done. From the conference proceedings, one clear barrier identified to teaching quality improvement was a hospital culture which does not value quality improvement. Perhaps better understanding of the effect on patient outcomes would foster a culture in which resident physician involvement in quality improvement projects was made a priority. At the level of the faculty and resident physician interface, another barrier to engaging trainees is time constraints and overseeing multiple simultaneous quality improvement projects. ${ }^{34} \mathrm{~A}$ third barrier to effective quality improvement training is the lack of best practices and data to evaluate the effectiveness of the quality improvement teaching experience.

The conference attendees identified several ways to include resident physicians in meaningful "real life" quality improvement work. Examples included assigning resident physicians to root cause analysis teams and hospital patient safety committee meetings. Interdisciplinary morbidity and mortality case conferences should include a systems analysis component so that resident physicians learn how to analyze and carry out system fixes. Resident physicians should be required as part of their training to identify a real system problem, and devise a project to fix it. 


\section{Recommendations on training in quality improvement}

- Quality improvement and patient safety measures in hospitals require the participation of resident physicians; the ACGME should specify in their core competency requirement that resident physicians work on quality improvement projects. Likewise, the Joint Commission should require that resident physicians be included in quality improvement and patient safety programs at teaching hospitals. Hospital administrators and residency program directors should create opportunities for resident physicians to become involved in ongoing quality improvement projects and root cause analysis teams. Feedback on successful quality improvement interventions should be shared with residents and broadly disseminated

- Quality improvement/patient safety concepts should be integral to the medical school curriculum. Medical school deans should elevate the topics of patient safety, quality improvement, and teamwork. These concepts should be integrated throughout the medical school curriculum and reinforced throughout residency. Mastery of these concepts by medical students should be tested in the United States Medical Licensing Examination steps

- Federal government should support involvement of resident physicians in quality improvement efforts. Initiatives to improve quality by including resident physicians in quality improvement projects should be financially supported by the Department of Health and Human Services

\section{Monitoring and oversight of the ACGME}

"The committee concludes that the advantages of a strengthened ACGME monitoring process along with external oversight by both CMS and the Joint Commission would help assure the public that programs would be more likely to adhere to the rules, problems with duty hours compliance would be uncovered and dealt with properly, and there would be more rapid implementation of the committee's recommended adjustments to duty hours."

Resident Duty Hours: Enhancing Sleep, Supervision and Safety (Medicine 2009, p. 81)

"It's important that the public has trust in us. We've probably lost that trust and lost the trust in ourselves."

David B. Sweet, $M D$

Program Director, Internal Medicine, Summa Health System, Akron, $\mathrm{OH}$

Harvard IOM Conference June 18, 2010
On June 17, 2010, the first day of the conference, participants were fortunate to hear a presentation from Dr Thomas Nasca, president and chief executive officer of the ACGME. Dr Nasca reported that, after publication of the Institute of Medicine study, the ACGME "convened the profession" to determine the best way to go about setting new standards. The process included the formation of a task force in May 2009 to review literature and testimony from organizations and individuals. Key elements were identified, which Dr Nasca described as:

- Supervision

- Graded authority and responsibility

- Handovers and continuity of care from the patient's standpoint

- Resident, residency, graduate medical education "enterprise" engagement in patient safety and quality improvement programs

- Range of sensitivity to fatigue

- Resident safety

- Impact of proposed changes on maturation of professionalism

On the issue of compliance, Dr Nasca emphasized that the ACGME "chose to take this on rather than give it to another entity because professional self-regulation is very important to us". The ACGME believes that compliance with the new standards can be improved with the introduction of an annual Sponsor Site Visit Program. He told conference participants these site visits "could be unannounced," that the sponsoring institution's chief executive officer would be held responsible for the accuracy of the information provided, and that after the first year, the site visit information would be published on the ACGME website, so that "the degree of compliance or quality of education milieu will be ascertained in this visit and be publicly disclosed."

Asked if this change were sufficient to assure the public, Dr Nasca replied: "We will leave it to them to tell us whether we've done enough. The ACGME is making its best effort to provide transparency and accountability. I don't know what else we can do. We anticipate a significant amount of push-back from teaching hospitals, and we're trying to make this (monitoring) as inexpensive as possible."

Dr Nasca explained that there would be a 90-day comment period following publication of the proposed new rules, and that the ACGME would announce its final rules at the end of September 2010, with implementation of the new rules required by July 1, 2011. 
Funding for the preannounced visits will come from additional fees charged to each institution. Dr Nasca explained that there are almost 9000 residency programs and that to monitor each annually would cost upwards of \$50 million. However, limiting the annual visits to the 700 sponsoring institutions was believed to be a realistic goal. The ACGME will produce an annual report of each visit, noting deficiencies that must be corrected, although it was not clearly stated what the repercussions for unchanged deficiencies would be.

The Institute of Medicine report recommends external oversight and monitoring of the ACGME in addition to strengthening internal oversight of the ACGME. The conference focused on how best to ensure that change happens in a self-regulated profession that has historically resisted change and has organizational members (eg, the American Hospital Association, the American Medical Association, the Association of American Medical Colleges, and the many medical and surgical specialty organizations) that have clearly articulated their opposition to implementation of many of the Institute of Medicine recommendations.

Conference attendees noted that physician self-regulation tests the trust of the public. One conference participant who was a patient advocate described her shock upon learning that the ACGME was made up almost entirely of doctors. Patients assume that there is government oversight over all aspects of medicine and graduate medical education, but even though hospitals receive nearly $\$ 10$ billion a year in Medicare funding, there is little government oversight of graduate medical education.

The Institute of Medicine report questions a medical culture that does not promote adherence to working hour limits: "The level of adherence to resident duty hour limits has raised questions about the current approach to monitoring duty hours and whether the culture of expectation, if not overt intimidation, results in pressure on resident physicians to work more than their assigned hours." ${ }^{18}$ Service and cultural pressures and commitment to their patients ensure that resident physicians will stay until the work gets done, no matter what rules are put on paper.

As one conference participant stated, "The problem is us - until we really believe this (reducing hours) makes a difference, we won't get the change we need to get." Culture change is needed, but how will it happen quickly enough to satisfy public safety concerns?

The Institute of Medicine report determined that selfregulation was simply not sufficient and that, in order to ensure proper oversight, external pressure was required in the form of both the Centers for Medicare and Medicaid Services and the Joint Commission. Both organizations have important roles in public oversight of patient safety and quality care. The problem is that there is no easy mechanism to invoke their involvement.

Clearly, the Centers for Medicare and Medicaid Services and the Joint Commission hold considerable sway over physician residency training. The Centers for Medicare and Medicaid Services controls most of graduate medical education funding, ie, $\$ 9.19$ billion in 2009 , according to data presented by Michelle Lefkowitz, a conference participant:

- $\$ 2.66$ billion is a direct graduate medical education payment, which partially compensates for residency education costs, eg, salaries of staff, resident physicians, and other direct costs

- $\$ 6.53$ billion is an indirect medical education payment, which partially compensates for higher patient care costs due to presence of teaching programs (see Table 5)

The Centers for Medicare and Medicaid Services depends upon ACGME accreditation of a residency program before it will reimburse the hospital at the agreed upon graduate medical education rate (which varies from hospital to hospital). The Centers for Medicare and Medicaid Services reimburses the hospital for the number of residency slots it has been approved for, ie, the resident physician "cap".

The Medicare Policy Advisory Commission released a study in June 2010 identifying $\$ 3.5$ billion each year in indirect medical education overpayments to hospitals, ie, payment above empirically justified indirect medical education costs. The Medicare Policy Advisory Commission recommended that Congress authorize the Secretary of Health and Human Services (which oversees the Centers for Medicare and Medicaid Services) to change Medicare's funding of graduate medical education to "better support the workforce skills needed in a delivery system that reduces cost growth while maintaining or improving quality." The Medicare Policy Advisory Commission also recommended that the secretary identify standards for redirecting this indirect medical education overpayment in the form of incentive payments to institutions that have incorporated "practice-based learning and improvement, interpersonal and communication skills, professionalism and systems-based practice" into their graduate medical training.

Implementation of the Institute of Medicine recommendations on working hours limits and workload, and the necessary work redesign that would be necessary to achieve those limits, could conceivably be included as one of the factors that the Health and Human Services Secretary and the Centers for Medicare and Medicaid Services considered in eligibility for incentive payments. It must be noted that the Centers for 
Table 5 The Institute of Medicine on external oversight of ACGME

The Centers for Medicare and Medicaid Services

"CMS has an Office of Clinical Standards and Quality (OCSQ) that serves as a focal point for all quality and safety issues and it has direct access to funds from the Medicare Trust Fund that support contracts for research and evaluation related to quality and safety. A very small percentage of those funds could support periodic contracted evaluations of duty hours and their monitoring and their relationship to quality of care, patient safety, resident safety and educational outcomes. CMS could either contract for studies of duty hour compliance and manage the contracts directly or it could support research managed by another federal agency, such as AHRQ. Alternatively, OCSQ also has ongoing contracts with private quality improvement organizations in each state, such as IPRO in New York, and could support one or more of them to conduct an evaluation of the outcomes of ACGME monitoring on adherence to rules."
The Joint Commission

"The oversight role for the Joint Commission would differ from that of CMS and should fit consistently with its own accreditation process, which focuses on patient safety and quality during periodic, unannounced visits to institutions by a team of surveyors. Testimony by the Joint Commission on its approach to monitoring quality of care and safety indicated that rather than monitoring whether resident duty hours met ACGME limits within an institution, the Joint Commission's approach could be to determine whether resident physicians or other staff were involved in patient safety events examined through patient-centered tracer cases and whether fatigue was a contributing cause."

Sleep, Supervision and Safety, p. 78-80
Medicare and Medicaid Services follows statutory formulae that do not currently provide for payment to be made for or based on quality or safety improvements or measures.

The 2010 Patient Protection Affordable Care Act ${ }^{35}$ created a Centers for Medicare and Medicaid Services center for quality, with funding for innovative pilot programs on health care delivery reform aimed at enhancing quality and safety. One clear area which the Centers for Medicare and Medicaid Services could help foster would be to fund resident physician and patient safety programs that improve delivery of care and decrease medical errors (see Table 6).

Just as the Centers for Medicare and Medicaid Services reimburses for graduate medical education expenses based on the ACGME's statement that a residency program is accredited, so too the Centers for Medicare and Medicaid Services reimburses health care facilities based on certification by the Joint Commission. Four existing Joint Commission requirements (staffing effectiveness, training programs, handover communication, and organizational leadership) speak to issues raised by the Institute of Medicine recommendations. Considering that an estimated one out of every four physicians working in US hospitals is a resident physician, the Joint Commission could do more under its existing mandate to ensure that resident physicians are incorporated into all other aspects of its quality and patient safety accreditation program.

In addition, the Joint Commission could establish a National Patient Safety Goal related to fatigue management for all health care workers. Patient safety goals (eg, patient handovers and handwashing) are powerful tools to make hospitals focus on a particular problem which will eventually become a Joint Commission requirement.
In addition to improved oversight by Centers for Medicare and Medicaid Services and the Joint Commission, conference attendees also discussed the Island Peer Review Organization model from New York State. For more than 20 years, the Department of Health has had regulations with the ability to hand out financial penalties to hospitals in New York State not in compliance with its resident physician work hours and supervision requirements. For the last 10 years, state funding has been in place for an aggressive compliance enforcement program via the Island Peer Review Organization (IPRO) as an independent contractor (see Table 7).

\section{Recommendations on monitoring and oversight of the ACGME}

- Make comprehensive fatigue management a national patient safety goal for the Joint Commission. Fatigue is a safety concern not only for resident physicians, but for nurses, attending physicians, and other health care workers. The Joint Commission should seek to ensure that all health care workers, not just resident physicians, are working as safely as possible

- Federal government (Centers for Medicare and Medicaid, Healthcare Research and Quality) should encourage the development of comprehensive fatigue management programs which all health systems would eventually be required to implement

- Make ACGME compliance working hours a "condition of participation" for reimbursement of direct and indirect graduate medical education costs. Financial incentives will greatly increase the adoption of and compliance with ACGME standards 
Table 6 A lesson from aviation

My first year spent on the wards I started with surgery....I was sitting in the clinic the Friday of my second week when all the residents got their biweekly email to fill out "time sheets." The things that were said about those time sheets cannot be repeated here, but needless to say they felt insulted by the exercise. Their time sheets were almost identical, always 12 hours per day during the week and 30 hours if they were on call either Friday or Saturday. The time sheets were a farce and the residents knew it. I imagine that everyone else knew it too, but no one cared because the documentation showing that surgery residents were not working more than 80 hours a week was complete and on file. This is a perfect example why... the current system within ACGME is inadequate. We often like to make analogies between patient safety and the airline industry, like the use of check lists or the limitation of hours to prevent fatigue and increase vigilance. Here's one more - it is the Federal Aviation Agency (FAA) that is responsible for regulating civil aviation to promote safety. However, it is the National Transportation Safety Board (NTSB) - an independent agency that is responsible for accident investigation. The FAA and NTSB have separate spheres of influence but still work together for passenger safety. The ACGME should set regulations much like the FAA, but there needs to be an independent agency like the NTSB that can offer robust oversight. In New York this separation of regulatory body (the Department of Health) and oversight (IPRO) is already happening.

John Brockman, 4th year Medical Student, Case Western Reserve University President, American Medical Student Association Harvard IOM Conference presentation June 18, 2010

\section{Future financial support for implementation}

"To avoid having residents bear the burden of implementing the duty hour recommendations by increasing their workload and increasing the risk to patient safety (as was done in 2003) additional funds are needed from all existing as well as new sources".

Resident Duty Hours: Enhancing Sleep, Supervision and Safety (Medicine 2009, p. 22)

"If this is just about sleep and shift work, it will never rise to the level of attention necessary to capture the political will for change".

Kavita Patel, MD, MSHS

Director of Health Policy, New America Foundation

Harvard IOM Conference presentation, June 18, 2010
The Institute of Medicine's report estimated that $\$ 1.7$ billion (in 2008 dollars) would be needed to implement its recommendations. Twenty-five percent (\$376 million) of that amount will be required just to bring hospitals into compliance with the existing 2003 ACGME rules. ${ }^{18}$ The committee recommended that all financial stakeholders in graduate medical education "financially support the changes ... to promote patient safety and resident safety and education, stressing that particular attention be paid to safety net hospitals." ${ }^{36}$ It also called for an independent convening body to bring together the major funders to "develop a coordinated approach to generate needed resources." "18

Examining the history of graduate medical education funding may point to a solution to the funding reform needed. Graduate medical education funding was first authorized by

Table 7 The IPRO experience - enforcing the bell regs in New York state

\begin{tabular}{ll}
\hline 1984 & Resident physician work hours received public attention after death of Libby Zion in NYC. \\
1987 & NYS forms Bell Commission and becomes only state to establish work hour regulations for medical training programs: Bell \\
& Regulations: 80 hours/week (no averaging); Limit on consecutive on-call shifts $24+3$ additional hours; 8 hours off between \\
assignments, I day off/week (no averaging); ER shifts I 2 hours. \\
Surprise inspections of I 2 NY hospitals find them in flagrant violation of Bell Regs. \\
1998 & Cardiology fellow dies in car accident after night on call - raises public attention. \\
1999 & NYS legislature provides funding for monitoring of hospitals for Bell compliance. \\
2000 & IPRO awarded 3 year contract to monitor and begins annual unannounced survey visits to every teaching hospital in the \\
2001 & state. Resident physicians -and the public - can contact IPRO directly to report violations. \\
Cost & Approximately $\$ 18,000$ per facility for an annual visit. \\
2005 and 2010 & IPRO awarded 3 year grant renewals.
\end{tabular}

Lessons Learned: Unannounced visits are key - Examine records, interview residents, look to see what non-physician work residents are doing. Work with hospitals and encourage quality improvement initiatives. Fines from $\$ 5,000$ to $\$ 20,000$ per citation on the Hospital Board and CEO are taken seriously. Have increased compliance from 36 to $93 \%$ by working with stakeholders (hospitals, hospital associations, NYS Department of Health and Committee of Interns and Residents).

Veronica Wilbur RN, BSN, MBA, Senior Director, IPRO New York State Harvard IOM Conference presentation, June 18, 2010 
Congress in 1965 as part of Medicare to ensure that there were enough physicians to care for the nation's elderly. At the time, this funding was not seen as permanent, nor the sole source of funding for the training of doctors. Today, 45 years later, Medicare remains the largest funder, providing $\$ 9.19$ billion in $2009^{23}$ of physician training, but it is not the only source..$^{18}$ A confusing patchwork of funders contributes to the lack of accountability and the difficulty in creating a more rational, transparent payment system for the training of physicians.

Many teaching hospitals are struggling financially, especially the safety net hospitals. Located in urban communities and serving largely uninsured and immigrant populations, the safety net hospitals train a large share of the nation's doctors, but receive disproportionately less in Medicare graduate medical education funding because they serve a younger population. At the same time, it is widely recognized that many teaching institutions are wasteful and inefficient. Initiatives to reduce hours, improve supervision, and redesign work processes (including reduced workload) like those described earlier are likely to contribute to more efficient, better prepared hospital discharges, shorter lengths of stay, and fewer preventable medical errors. These quality improvements will, in turn, produce savings that will help to offset the cost of hiring additional personnel (see Table 8).

The Institute of Medicine report estimates that its recommendations could reduce preventable adverse events, but the savings do not all accrue to the same source that incurs the immediate cost, ie, the teaching hospital. Thus hospitals are not provided with a monetary incentive to address the expense of redesign of resident physician work hours, as hospitals do not always enjoy the savings due to improved resident physician work hours (see Figure 1).

Still, a strong business case can be made for hospitals to adopt the Institute of Medicine changes in the context of the goals and incentives set out in the Affordable Care Act. The rationale for implementing the Institute of Medicine recommendations should not focus solely on the benefits of reducing work hours per se. Rather, the focus should be on improving the overall health care delivery system to reduce waste and inefficiency and improve patient safety. As with virtually all other aspects of our health care system, the driver of change will be the flow of money, ie, what do we pay for and who do we pay?

As the single largest health care payer in the US, Medicare sets the innovation standards and the Secretary of Health and Human Services has purview over quality and funding initiatives. Change could potentially be funded through this administrative action. The Medicare Policy
Advisory Commission has recently recommended realigning Medicare funding of graduate medical education in such a way that could also encompass funding for implementing some or all of the Institute of Medicine recommendations. In its June 2010 report, the advisory body called on the secretary of Health and Human Services to reallocate that portion of teaching hospitals' indirect medical education payments above empirically justified amounts to teaching hospitals that train resident physicians "on skills essential for delivery system reform, such as quality measurement and improvement, evidence-based medicine, multidisciplinary teamwork, care coordination across settings and health information technology." While the Medicare Policy Advisory Commission is strictly an advisory body, the Independent Payment Advisory Board established by the Affordable Care Act will begin its work in 2014 with much greater authority.

In the meantime, the National Health Care Workforce Commission established by the Affordable Care Act began its work in September 2010 (see Table 9). Its charge is to review and project health care workforce needs and to provide comprehensive, independent information to lawmakers on how to align resources with national need. ${ }^{37}$ Irrespective of the Institute of Medicine recommendations, there has been a push in academic medical circles to lift the cap on the number of residency slots that Medicare will fund. The workforce commission will have to address specialty training priorities, the training they receive (eg, teamwork and quality improvement), and the safe conditions under which resident physicians are trained and patients receive care. ${ }^{35}$

Bringing all graduate medical education funders together to develop a coordinated approach to funding the Institute of Medicine recommendations is daunting, given the relatively large and diverse group of players. The Medicare Policy Advisory Commission has discussed proposals to restructure graduate medical education funding by transitioning to a general revenue financing model, with a dedicated line item in the federal budget. ${ }^{38}$ Besides rationalizing the current patchwork system, this move would enhance physician workforce analysis and pipeline strategies (eg, increasing the number of primary care physicians) as well as building support for educational standards (eg, the teaching of teamwork and quality improvement).

\section{Recommendations on future financial support for implementation}

- The Institute of Medicine should convene a panel of stakeholders, including private and public funders of 
Table 8 Costing out the IOM recommendations

Estimated $\$ 1.7$ billion cost is based on replacing the equivalent of 8,247 resident physicians

- Attending physicians: 5,00I

- Mid-level practitioners: 5,984

- Licensed vocational nurses: 320

- Nursing aides: 229

- Laboratory technicians: 45

- Increasing residency slots is another option

\section{Some caveats on the cost estimates}

- No reliable data on total work hours by specialty

- Considered only reduction in resident physician work hours

- Did not consider the cost of other recommendations

- Increasing supervision

- Resident physician transportation

- Compliance monitoring

- Assumed I-to-I replacement ratio

- Did not consider potential savings from work and education redesign and ways to reduce resident physician hours without replacement costs

Putting the $\$ 1.7$ billion cost estimate into perspective

- For the average hospital

- Estimated cost is $\$ 1.3$ million

- Cost per admission is $\$ 89.61$

- Total costs represent

- About $9 \%$ of total funding for GME costs

$-0.4 \%$ of Medicare outlays

- Impact on preventable adverse events is not known

$-7 \%$ reduction would yield societal savings that offset cost of reducing resident physician hours

Barbara Wynn

Senior Health Policy Analyst, Rand Corporation using data from Nuckols and Escarce, 2005 and Sleep, Supervision and Safety, IOM 2009

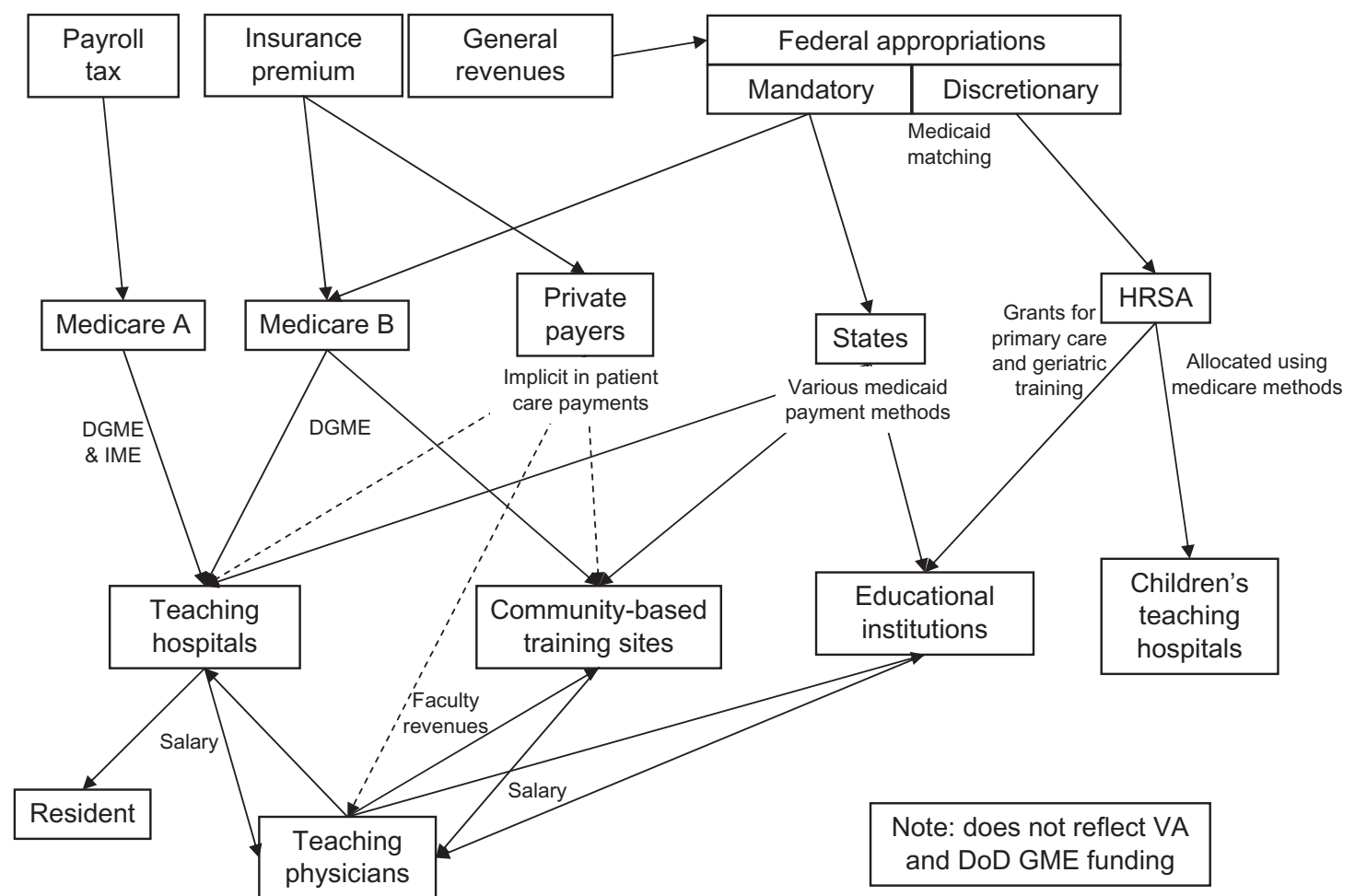

Figure I Flow of funds under current GME financing system.

Barbara Wynn/Rand Corporation 
health care and graduate medical education, to lay out the concrete steps necessary to identify and allocate the resources needed to implement the recommendations contained in the IOM "Resident duty hours: Enhancing sleep, supervision and safety" report. The conference participants suggested several approaches to engaging public and private support for this initiative.

- Efforts to find additional funding to implement the Institute of Medicine recommendations should focus more broadly on patient safety and health care delivery reform; policy efforts focused narrowly upon resident work hours are less likely to succeed than broad patient safety initiatives that include residency redesign as a key component

- Hospitals should view the Institute of Medicine recommendations as an opportunity to begin resident physician work redesign projects as the core of a business model that embraces safety and ultimately saves resources

- Both the Secretary of Health and Human Services and the Director of the Centers for Medicare and Medicaid Services should take the Institute of Medicine recommendations into consideration when promulgating rules for innovation grants

- The National Health Care Workforce Commission should consider the Institute of Medicine recommendations when analyzing the nation's physician workforce needs

\section{Individual vulnerabilities and implications for policy}

"Whenever I have presented data on the average impact of sleep loss on performance, the most common question that I have been asked is about interindividual differences. 'Aren't some people more resistant to the effects of sleep loss than others?' The follow-up comments by such questions usually reveal an underlying premise that individuals in certain professions (physicians, surgeons, special forces, astronauts) may be more resistant than the average person to the effects of acute sleep loss or chronic sleep restriction on performance. In fact, even among healthy young adults, there are profound interindividual differences in the impact of sleep loss on performance. In addition, healthy sleepers are likely to be much more resistant to the effects of sleep loss than the 50-70 million Americans who suffer from chronic disorders of sleep and wakefulness."

Charles A. Czeisler, PhD, MD

Chief, Division of Sleep Medicine, Brigham

and Women's Hospital

Harvard IOM Conference presentation, June 18, 2010

There are many factors that may lead to interindividual differences in the average amount of sleep obtained by residents working the same number of hours in the hospital, including differences in their responsibilities outside the

Table 9 Public perception of resident physician work hours and patient safety

- Stratified random sample of 1200 American households (Nov/Dec 2009)

- + - $2.8 \%$ margin of error

- Findings were consistent across geographic and party lines and similar for different racial groups and people working inside or out of the healthcare professions.

- $1 \%$ of the general public supports shifts longer than 24 hours for resident physicians.

- The majority of respondents said they believe that resident physicians work shifts of 12 hours or less.

- $81 \%$ of respondents believe that reducing resident physician work hours would be very or somewhat effective in reducing medical errors.

- $81 \%$ of respondents believe that patients should be informed if a treating resident physician has been working for more than 24 hours.

- $80 \%$ said they would then want a different doctor.

- Four of five respondents support limiting the duration of individual work shifts to 16 hours, capping weekly work hours at a maximum of 80 hours in any single week and ensuring that medical residents have at least one day off per week.

- $68 \%$ favor the IOM recommendation that resident physicians not work more than 16 hours over an alternative IOM proposal that would permit resident physicians to remain in the hospital for 30 hours, as long as they were provided the opportunity to sleep for five hours without interruption after 16 hours of work.

- $91 \%$ of respondents believe that strict rules should be established to ensure that resident physicians are provided with direct, on-site supervision by more experienced doctors.

Results of Public Opinion poll published in BMC-Medicine (Blum, Raiszadeh et al. 2010), presented by Helen Haskell, Founder and President, Mothers Against Medical Error

Harvard IOM Conference, June 17, 2010 
hospital, eg, new mothers and fathers. Recent investigations have also identified genetic polymorphisms, sleep disorders, and other interindividual differences that appear to convey an increased vulnerability to the performance-impairing effects of 24 hours of wakefulness. These include:

- Age-related differences in the vulnerability to sleep loss (young adults, who make up the majority of resident physicians, are most severely affected by acute sleep deprivation)

- Trait differences in vulnerability to sleep loss

- Genetic polymorphisms (present in about $10 \%-15 \%$ of the population) may account for differences in the tolerability of acute sleep loss

- Sleep-related breathing disorders (obstructive sleep apnea/hypopnea)

- Shift work disorder

- Insomnia

- Narcolepsy

- Sleep disturbance secondary to a number of psychiatric disorders and other conditions, including burnout, anxiety, and mood disorders (depressive disorders and bipolar disorder)

Given the magnitude of interindividual differences in the effect of sleep loss on cognitive performance and the sizeable proportion of the population affected by sleep disorders, hospitals and the medical profession face a number of ethical dilemmas. In the spirit of the dictum to "do no harm," advances in understanding the medical and genetic basis of interindividual differences in performance, vulnerability to sleep loss should be incorporated into the development of work-hour policy limits for both physicians and surgeons. ${ }^{30}$

Charles A. Czeisler, MD, PhD

Chief, Division of Sleep Medicine, Brigham and Women's Hospital

Harvard IOM Conference presentation,

June 18, 2010

\section{Future research}

"Systemic collection of pertinent data would help monitor and evaluate the effects of implementing the recommendations, and research would provide an evidence base for future changes to duty hours or educational strategies."

Resident Duty Hours: Enhancing Sleep, Supervision and Safety (Medicine 2009, p. 295)
"We are great at generating new knowledge, but bad at implementation."

James B. Battles, PhD

Social Science Analyst for Patient Safety, Agency for Healthcare Research and Quality

Harvard IOM Conference presentation, June 18, 2010

The IOM "Sleep, supervision and safety" report noted that "... the lack of systematic data collection before and after the 2003 rules hampered the committee's ability to determine their impact fully and to assess how much of the complaints about duty hour reform represent rhetoric and resistance to change rather than valid criticisms." ${ }^{.18}$

Recognizing that "because so many individuals and organizations have strong economic and professional interests in GME, and resident physician duty hours in particular, it will be a challenge to come up with an agenda for research projects," the Institute of Medicine called up the ACGME to convene a meeting of stakeholders and potential funders to set priorities for research and evaluation projects. ${ }^{18}$

Conference participants concurred that convening the stakeholders and agreeing on a research agenda was key. Some observed that elements of the medical education community have been reluctant to act on the data. "If it wasn't about work hours reduction, would any other evidence be ignored if it showed that errors could be reduced by $36 \%$ ?" posited Steven W Lockley. "We need to agree on the research agenda and how to fund it."

Several logical funders for future research were identified. The Agency for Healthcare Research and has set aside funds for studying working conditions and the Center for Quality Improvement and Patient Safety, created by the Affordable Care Act, will fund a new blueprint for Agency for Healthcare Research and research activities around patient safety. The Health Resources and Services Agency also has funding through Title 7, ie, graduate medical education.

But above all other agencies, the Centers for Medicare and Medicaid is the only stakeholder that funds graduate medical education upstream and will reap savings downstream if preventable medical errors are reduced as a result of resident physician work hours reform. The Centers for Medicare and Medicaid has the capacity and funding to study what works to improve quality and patient safety and to promote pilot projects which incentivize redesign and education of resident physician work hours.

Until Congress changes the law and modifies graduate medical education payments to instruct the Centers for Medi- 
care and Medicaid to act on the evidence and begin to provide incentives for redesign of residency training, no manner of evidence is likely to move those who are opposed to reform into action.

\section{Opportunities for research}

Throughout the two-day conference, participants identified a number of research opportunities. These are:

- What are resident physicians doing with their time in the hospital? What percentage is spent on educational activities? What percentage is spent on clinical duties?

- How to develop clear guidelines for resident physician workloads?

- Study home call further to determine if excessive home call (eg, broken sleep throughout the night) affects quality of patient care

- A "Commonwealth Fund"-type study of other countries' work hour rules to study the effects on workforce, patient safety and education

- Research adequate time frames for clinical training

- How do we educate medical students in a manner that motivates them to pursue certain medical specialties?

- How do we promote teamwork and not working in isolation using the ACGME resident physician competency structure?

- What are the real economic impacts of good and bad handovers?

- Develop specific protocols for various types of handovers required in different clinical settings

- How can clinical training be optimized without exceeding work hour limits?

\section{Conclusion}

The difficulties in implementing the recommendations contained in the Institute of Medicine's "Sleep, supervision and safety" report should not be underestimated. Any change involving literally hundreds of thousands of physicians and physicians in training, more than a thousand hospitals, and a global budget in the billions, is daunting. This difficulty is compounded by the depth to which the structure of residency programs is embedded in the fabric of hospitals and medical culture. Despite the deepseated feelings that the residency experience engenders among physicians who have gone through this intensive training, there is an urgent need for reform. Just as evidence-based medicine fundamentally altered the manner in which physicians evaluate therapies and decide upon their use in the care of their patients, so too must science inform decisions about the organization of medical training programs. After evaluating this growing body of evidence, the Institute of Medicine concluded that the status quo is unsafe and that evidence-based changes to residency must be made. We concur.

Besides the specific recommendations contained in this White Paper, several themes weaved their way through the conference proceedings as participants confronted these difficulties.

Medical education innovators are already acting on the evidence assembled by the Institute of Medicine report. They are redesigning their educational and clinical programs, with active involvement of resident physicians, and despite initial serious concerns, both resident physicians and faculty are pleased with the results. As these best practices spread, more fourth-year medical students are likely to seek out these residency programs over the more traditional training experiences.

The biggest obstacle to change is culture. The profession needs to reconsider what it means to be a professional in the age of teamwork, eg, the "lone provider" versus team responsibility for the patient. When does knowing one's own limits take precedence over endurance in the interest of patient care? Building the political will and making the changes needed in the reimbursement mechanisms to implement the Institute of Medicine recommendations require focusing on patient safety and quality of care.

What is required to implement the Institute of Medicine recommendations? No consensus was reached on this critical issue, but three concepts surfaced and resurfaced throughout the two day conference:

- Some regulations may be necessary to jumpstart needed change

- Financial incentives should be provided to reward innovation

- The profession has to take professional pride and ownership of the change in order for it to be done right This white paper is an effort to begin that discussion.

\section{Acknowledgments}

This conference and White Paper was funded by the CIR Policy and Education Initiative.

We are grateful to the following people who participated in the two-day roundtable discussion that produced this white paper: James B Battles, Maureen Bisognano, John Brockman, Claire C Caruso, David I Cohen, Jordan J Cohen, John R Combes, Charles A Czeisler, Jennifer Domingo, Edward J Dunn, Helen Haskell, Joel T Katz, Christopher P 
Landrigan, Lucian Leape, Michelle Lefkowitz, Arthur Aaron Levin, Steven W Lockley, Kavita Patel, Ann Louise Puopolo, Farbod Raiszadeh, Wendy Reid, Paul M Schyve, Chicago, IL; David B Sweet, James F Whiting, Veronica Wilbur and Barbara O Wynn. Biographies of attendees can be found in Appendix D. The conference organizers very much appreciated ACGME President and CEO Dr Thomas Nasca presenting to conference participants on June 17, 2010. Thanks also to Elizabeth J McClean from the Cornell University School of Industrial and Labor Relations for her transcription work and to Stacy De-Lin and Heather Appel for their assistance prior to and on June 17-18, 2010.

\section{Disclosure}

Dr. Blum is an employee of Mount Sinai School of Medicine and a paid consultant to the Committee of Interns and Residents of the Service Employees International Union (CIR/ SEIU). Dr. Czeisler has received consulting fees from or served as a paid member of scientific advisory boards for: Bombardier, Inc.; Boston Celtics; Cephalon, Inc.; Delta Airlines; Eli Lilly and Co.; Global Ground Support; Johnson \& Johnson; Koninklijke Philips Electronics, N.V.; Minnesota Timberwolves; Portland Trail Blazers; Respironics, Inc.; Sleep Multimedia, Inc.; Somnus Therapeutics, Inc.; Vanda Pharmaceuticals, Inc.; and Zeo Inc. Dr. Czeisler owns an equity interest in Lifetrac, Inc.; Somnus Therapeutics, Inc.; Vanda Pharmaceuticals, Inc., and Zeo Inc., and received royalties from the Massachusetts Medical Society/New England Journal of Medicine; McGraw Hill, the New York Times Penguin Press and Philips Respironics. Dr. Czeisler has received lecture fees from the American Academy of Sleep Medicine; National Academy of Sciences; National Sleep Foundation; New England College of Occupational and Environmental Medicine (NECOEM); North East Sleep Society; Rockpointe; the University of Chicago and the University of Colorado.

Dr. Czeisler has also received clinical trial research contracts from Cephalon, Inc., and Merck \& Co., Inc.; an investigatorinitiated research grant from Cephalon, Inc.; a research prize with monetary award from the American Academy of Sleep Medicine; and his research laboratory at the Brigham and Women's Hospital has received unrestricted research and education funds and/or support for research expenses from Cephalon, Inc., and ResMed. The Harvard Medical School Division of Sleep Medicine (HMS/DSM), which Dr. Czeisler directs, has received unrestricted research and educational gifts and endowment funds from: Boehringer Ingelheim Pharmaceuticals, Inc., Cephalon, Inc., George H. Kidder, Esq., Gerald McGinnis, GlaxoSmithKline, Herbert Lee, Hypnion, Jazz Pharmaceuticals, Jordan's Furniture,
Merck \& Co., Inc., Peter C. Farrell, Ph.D., Pfizer, ResMed, Respironics, Inc., Sanofi-Aventis, Inc., Sealy, Inc., Sepracor, Inc., Simmons, Sleep Health Centers LLC, Spring Aire, Takeda Pharmaceuticals and Tempur-Pedic. The HMS/ DSM has received gifts from many outside organizations and individuals including: Catalyst Group, Cephalon, Inc., Committee for Interns and Residents, Eisai, Inc., Farrell Family Foundation, Jordan's Furniture, Lilly USA, LLC, Neurocare Center for Sleep, Philips-Respironics, Inc., Praxair US Homecare, Select Comfort Corporation, Sleep HealthCenters LLC, Somaxon Pharmaceuticals, Vanda Pharmaceuticals, Inc., Wake Up Nacrcolepsy, Inc., Watermark Medical, and Zeo, Inc. The HMS/DSM Sleep and Health Education Program has received Educational Grant funding from Cephalon, Inc., Takeda Pharmaceuticals, Sanofi-Aventis, Inc. and Sepracor, Inc. Dr. Czeisler is the incumbent of an endowed professorship provided to Harvard University by Cephalon, Inc. and holds a number of process patents in the field of sleep/circadian rhythms (e.g., photic resetting of the human circadian pacemaker). Since 1985, Dr. Czeisler has also served as an expert witness on various legal cases related to sleep and/or circadian rhythms. Dr. Landrigan has served as a paid consultant to: Vital Issues in Medicine (developing an educational course for physicians on Shift Work Disorder. This work was supported by an educational grant from Cephalon, Inc. to Vital Issues in Medicine); and AXDev (to help develop a study of Shift Work Disorder. This work was supported by a grant from Cephalon, Inc. to AXDev). He is supported in part by the Child Health Corporation of America, for his work as an Executive Council member of the Pediatric Research in Inpatient Settings (PRIS) network. In addition, Dr. Landrigan has received monetary awards, honoraria, and travel reimbursement from multiple academic and professional organizations for delivering lectures on sleep deprivation, physician performance, and safety.

\section{References}

1. Brennan TA, Leape LL, Laird NM, et al. Incidence of adverse events and negligence in hospitalized patients. Results of the Harvard Medical Practice Study I. N Engl J Med. 1991;324:370-376.

2. Leape LL, Brennan, TA, Laird N, et al. The nature of adverse events in hospitalized patients. Results of the Harvard Medical Practice Study II. N Engl J Med. 1991;324:377-384.

3. Thomas EJ, Studdert DM, Burstin HR, et al. Incidence and types of adverse events and negligent care in Utah and Colorado. Med Care. 2000;38:261-271.

4. Institute of Medicine. To Err is Human: Building a Safer Health System. Washington, DC: National Academies Press; 1999.

5. Levinson DR. Office of the Inspector General, Department of Health and Human Services. Adverse events in hospitals: National incidence among Medicare beneficiaries. 2010. Available from: http://oig.hhs.gov/ oei/reports/oei-06-09-00090.pdf 
6. Kochanek KD, Murphy SL, Anderson RN, Scott C. Deaths: Final data for 2002. Natl Vital Stat Rep. 2004;53:1-115.

7. Landrigan CP, Parry GJ, Bones CB, Hackbarth AD, Goldmann DA, Sharek PJ. Temporal trends in rates of patient harm resulting from medical care. $N$ Engl J Med. 2010;363:2124-2134.

8. Sharek PJ, Parry G, Goldmann D, et al. Performance characteristics of a methodology to quantify adverse events over time in hospitalized patients. Health Serv Res. 2011;46:654-678.

9. Barger LK, Ayas NT, Cade BE, et al. Impact of extended-duration shifts on medical errors, adverse events, and attentional failures. PLoS Med. 2006;3:e487.

10. Ayas NT, Barger LK, Cade BE, et al. Extended work duration and the risk of self-reported percutaneous injuries in interns. $\mathrm{J} \mathrm{Am} \mathrm{Med} \mathrm{Assoc.}$ 2006;296:1055-1062.

11. Barger LK, Cade BE, Ayas NT, et al. Extended work shifts and the risk of motor vehicle crashes among interns. $N$ Engl $J$ Med. 2005;352:125-134.

12. Landrigan CP, Rothschild JM, Cronin JW, et al. Effect of reducing interns' work hours on serious medical errors in intensive care units. $N$ Engl J Med. 2004;351:1838-1848.

13. Lockley SW, Cronin JW, Evans EE, et al. Effect of reducing interns' weekly work hours on sleep and attentional failures. $N$ Engl J Med 2004;351:1829-1837.

14. Levine AC, Adusumilli J, Landrigan CP. Effects of reducing or eliminating resident work shifts over 16 hours: A systematic review. Sleep. 2010;33:1043-1053.

15. Reed DA, Fletcher KE, Arora VM, et al. Systematic review: Association of shift length, protected sleep time, and night float with patient care, residents' health, and education. Ann Intern Med. 2010;153:829-842.

16. Blum AB, Raiszadeh, Shea $\mathrm{S}$, et al. US public opinion regarding proposed limits on resident physician work hours. BMC Med. 2010;8:33.

17. Iglehart JK. Revisiting duty-hour limits - Institute of Medicine recommendations for patient safety and resident education. $N$ Engl J Med. 2008;359:2633-2635.

18. Institute of Medicine. Resident Duty Hours: Enhancing Sleep, Supervision, and Safety. Ulmer C, Wolman DM, Johns MME, eds. Washington, DC: National Academies Press; 2009.

19. Nasca TJ, Day SH, Amis ES; ACGME Duty Hour Task Force. The new recommendations on duty hours from the ACGME Task Force. $N$ Engl $J$ Med. 2010;363:e3.

20. Schwartz A, Bashok P et al. Conceptual framework in the study of duty hour changes in graduate medical education: An integrative review. Available from: www.acgme-2010standards.org/research-testimony.html. Accessed April 26, 2011

21. Caruso JW, Grasberger JV, Paskin DL, et al. Systemic review of the literature on the impact of variation in residents' duty hour schedules on patient safety, 2009. Available from: http://www.acgme-2010standards.org/pdf/Jefferson_Medical_College_Duty_Hours_Review. pdf. Accessed April 26, 2011.

22. Fletcher KE, Arora V. Systematic review of the literature: resident duty hours and related topics. Available from: www.acgme-2010standards. org/research-testimony.html. Accessed April 26, 2011.
23. Medicare Payment Advisory Committee. Report to the Congress: Aligning Incentives in Medicare. 2010. Available from: http://www. medpac.gov/documents/jun10_entirereport.pdf. Accessed April 26, 2011.

24. Medicare Payment Advisory Committee. Improving incentives in the Medicare program, 2009. Available from: www.medpac.gov/documents/ jun09_entirereport.pdf. Accessed April 26, 2011.

25. Petersdorf RG. Medical schools and the public interest: A conversation with Robert G. Petersdorf. Interview by John K Iglehart. Health Aff (Millwood). 1988;7(2 Suppl):108-120.

26. Singh H, Thomas EJ, Petersen LA, Studdert DM. Medical errors involving trainees: A study of closed malpractice claims from 5 insurers. Arch Intern Med. 2007;167:2030-2036.

27. McMahon GT, Katz JT, Thorndike ME, Levy BD, Loscalzo J. Evaluation of a redesign initiative in an internal-medicine residency. $N$ Engl J Med. 2010;362:1304-1311.

28. Philibert I. Sleep loss and performance in residents and nonphysicians: A meta-analytic examination. Sleep. 2005;28:1392-1402.

29. Rothschild JM, Keohane CA, Rogers S, et al. Risks of complications by attending physicians after performing nighttime procedures. JAMA. 2009;302:1565-1572.

30. Czeisler CA. Medical and genetic differences in the adverse impact of sleep loss on performance: Ethical considerations for the medical profession. Trans Am Clin Climatol Assoc. 2009;120:249-285.

31. Horwitz LI, Krumholz HM, Green ML, Huot SJ. Transfers of patient care between house staff on internal medicine wards: A national survey. Arch Intern Med. 2006;166:1173-1177.

32. Stevens DP, Sixta CS, Wagner E, Bowen JL. The evidence is at hand for improving care in settings where residents train. J Gen Intern Med. 2008;23:1116-1117.

33. Warm EJ, Schauer DP et al. The ambulatory long-block: an accreditation council for graduate medical education (ACGME) educationa innovations project (EIP). J Gen Intern Med. 2008;23(7):921-926.

34. Vinci LM, Oyler J, et al. Effect of a quality improvement curriculum on resident knowledge and skills in improvement. Qual Saf Health Care. 2010;19(4):351-354.

35. Patient Protection and Affordable Care Act (2010). Pub. L. 11-148, 124.

36. Institute of Medicine. Sleep disorders and sleep deprivation: An unmet public health problem. Colten HR, Altevogt BM, eds. Washington, DC: National Academies Press; 2006.

37. The Commonwealth Fund. Health Reform Resource Center, 2010. Available from: http://www.commonwealthfund.org/Health-Reform/ Health-Reform-Resource.aspx. Accessed April 26, 2011.

38. Boccuti C, Craig L. Restructuring medical education financing principles and priorities. MedPac meeting presentation, March 4, 2010. Available from: http://www.medpac.gov/meeting_search. cfm? SelectedDate=2010-03-04\%2000:00:00.0. Accessed April 26, 2011.

39. Skills for Health Healthcare Workforce Portal. The case for hospital at night - the search for evidence, 2008. Available from: www.healthcareworkforce.nhs.uk. Accessed April 26, 2011. 


\section{Appendix A}

The UK "Hospitals at Night" (HaN) work redesign: A team approach to maximize patient safety and enhance the resident training experience, summarized by Professor Wendy Reid, National Clinical Advisor, Department of Health for the Working Time Directive, London, UK.

\section{Background}

$\mathrm{HaN}$ is a work redesign intervention to address patient safety issues at night. It began with a few pilot sites in London in 2005 and has since spread across the UK as hospitals have implemented reduced resident physician work hours to comply with the European working time directive. There is a need to address care delivered at night because of:

- Specialties working in silos (eg, each service "covering its own")

- Sickest patients being seen first by the most junior resident physicians with minimal skills and competencies

- Minimal supervision

- Paging interrupting resident work and rest

- Nursing staff being unaware of doctors' competence

\section{Goals of $\mathrm{HaN}$}

- Minimize junior resident physicians' time spent in hospital at night

- Maximize resident physicians' access to training in day

- Increase patient safety - get the right person at the right time at the bedside

\section{How to think about implementing $\mathrm{HaN}$ in your hospital}

A) Analyze what happens in your hospital between $7 \mathrm{pm}$ and $7 \mathrm{am}$. In UK, medical educators found that evening work cascaded into the night, causing risk for patients, inefficiencies in the system, and inappropriate work for the most junior resident physicians. A likely result is:

- Ninety percent of the time, the work done by resident physicians between midnight and 7 am either should have been done the day or evening before, could have waited until the morning, or did not need to be done by a doctor

- Ten percent of the time the patient needed a doctor at the bedside immediately or within one hour

B) Maximize the work that gets done between $5 \mathrm{pm}$ and $9 \mathrm{pm}$ :

- Increase resident physician staffing if necessary to cover peak admitting time better

- Use attending time to make clinical decisions and improve safety and efficiency
- Analyze and work to correct inefficient hospital practices that may be pushing daytime tasks into the night (eg, laboratory problems, patient discharge delays)

C) Ask yourself what skills your patients need at night? Then:

- Assemble a multidisciplinary HaN team of resident physicians and nurses, with attending support to cover inpatient medical and surgical floors. Teams (size and composition) will vary depending upon the specifics of your hospital. Composition of the HaN teams varied; in rural hospitals a HaN team included two nurse practitioners and two junior resident physicians (UK equivalent of PGY 3); in a large urban hospital, the team had 11 members (all residents except for one nurse). Resident physicians on the $\mathrm{HaN}$ team are mostly, if not all, medical resident physicians. The team covered medical and surgical patients. Medical educators in the UK found that it was effective for the service and resident physician training for more senior surgical resident physicians (PGY 3 and above) to only be called in for genuine surgical emergencies and, because of their lack of training, not to have junior surgeons in house at night. This maximized sleep opportunities for surgical resident physicians at night, more daytime operating and training, and the patients were cared for by the appropriate level physician in emergencies. Neurology was largely covered by the HaN team with senior resident physicians on call from home. Psychiatry ran a separate service but used the HaN model in some areas to link nurses and doctors across a community

- Designate a leader, who in the UK is often a senior nurse, noting that there is a difference between leading the team and leading in a clinical situation

- The team meets for formal handover with the day team for about 30 minutes at approximately $9 \mathrm{pm}$ and then again at about $7 \mathrm{am}$. Handover focuses only on the patients who are of most concern so that everyone is aware. Note that HaN rounds do not take the place of the usual service team handover

- From $9 \mathrm{pm}$ to $7 \mathrm{am}$, all pages for HaN team oncall resident physicians are transferred to a senior nurse for triage. He/she is able to answer routine questions from floor nurses. When a doctor is required, the HaN leader is able to determine what level of competence/experience is needed so that the patient gets the assistance they need quickly

- Audit the outcome of calls to the HaN team and feedback the outcomes to all staff so that the "night silo" is broken down 


\section{Studying the $\mathrm{HaN}$ experience}

- HaN was first piloted in 2002 at five acute care hospitals and three nonacute hospitals, and has since been adopted by the majority of hospitals in the UK as an effective way to comply with the 2004 working time directive (reducing resident physician work hours) and improve patient safety

- A study by Skills for the Health-Workforce Projects Team 2008 (using information supplied and analyzed by the National Health Service Information Centre for Health and Social Care) assessed the impact and trends of the HaN implementation on single-site National Health Service hospitals. ${ }^{39}$ Published in 2008, the study found: a reduction in number of deaths within 48 hours of admission (greater than the all-English average); a reduction in number of deaths within 48 hours of surgery/procedure (greater than the all-English average); a reduction in both emergency and elective average lengths of stay; and, in the majority of sites studied, a reduction in the hospital standardized mortality ratio from the pre-HaN to postHaN implementation period

\section{Appendix B Institute of Medicine Report Resident duty hours: enhancing sleep, supervision, and safety ${ }^{18}$}

Reprinted with permission of the Institute of Medicine and the National Academies Press. Full text of the IOM report from which this summary is excerpted is available at: http:// www.iom.edu/Reports/2008/Resident-Duty-Hours-Enhancing-Sleep-Supervision-and-Safety.aspx.

To promote conditions for safe medical care, improve the education of doctors in training, and increase the safety of residents and the general public, the committee offers the following recommendations, which should be implemented with all deliberate speed. While some recommendations should be implemented immediately, changes to duty hours, adjustments in workload, and the funding needed for these changes might require an integrated phase-in. The recommendations will require additional resources, both financial and human. Without the necessary restructuring in resource allocation, attempts to implement the recommendations will fail to have the desired benefits and could even reduce patient safety. The committee believes that the Accreditation Council for Graduate Medical Education and the other organizations charged to implement aspects of the recommendations should begin their work with urgency and that action on all recommendations should be taken within 24 months.

\section{Recommendations on specific limits on duty hours}

The Accreditation Council for Graduate Medical Education (ACGME) should adopt and enforce requirements for residency training that adhere to the following principles: duty hour limits and schedules should promote the prevention of sleep loss and fatigue; additional measures should mitigate fatigue when it is unavoidable (eg, during night work and extended duty periods); and schedules should provide for predictable, protected, and sufficient uninterrupted recovery sleep to relieve acute and chronic sleep loss, promote resident wellbeing, and balance learning requirements. Programs should design resident schedules using the following parameters:

- Duty hours must not exceed 80 per week, averaged over four weeks

- Scheduled continuous duty periods must not exceed 16 hours unless a five-hour uninterrupted continuous sleep period is provided between $10 \mathrm{pm}$ and $8 \mathrm{am}$. This period must be free from all work and call, and used by the resident for sleep in a safe and sleep-conducive environment. The five-hour period for sleep must count toward total weekly duty hour limits. Following the protected sleep period, a resident may continue the extended duty period up to a total of 30 hours, including any previous work time and the sleep period

- Residents should not admit new patients after 16 hours during an extended duty period

- Extended duty periods (eg, 30 hours that include a protected five-hour sleep period) must not be more frequent than every third night with no averaging

- After completing duty periods, residents must be allowed a continuous off-duty interval of:

- a minimum of 10 hours following a daytime duty period that is not part of an extended duty period

- a minimum of 12 hours following a night float or night shift work that is not part of an extended duty period

- a minimum of 14 hours following an extended duty period; and residents should not return to service earlier than 6 am the next day

- Night float or night shift duty must not exceed four consecutive nights and must be followed by a minimum of 48 continuous hours off duty after three or four consecutive nights

- At least one 24-hour off-duty period must be provided per seven-day period without averaging; one additional (consecutive) 24-hour period off duty must be provided to ensure at least one continuous 48 -hour period off duty per month 
- In exceptional circumstances requiring the resident's physical presence to ensure patient safety or to engage in a critical learning opportunity, the program faculty may permit, but not require, residents to remain on duty beyond the scheduled time; programs must record the nature of each exception allowed for ACGME review

- These exceptions are not to become routine practice. Residency review committees should determine at the time of program reaccreditation whether the documented exceptions to scheduled duty hours warrant citation

- The ACGME should develop criteria for granting individual programs waivers from one or more of the above scheduling parameters; such criteria should be formulated only to accommodate rare, well documented circumstances in which patient safety and/or educational requirements of specific programs outweigh the advantages of full compliance with the committee's recommendations and cannot be addressed by means other than the requested waiver(s); programs that are granted waivers (if any) and the nature of those waivers should be posted on the public access portion of the ACGME website. Included in the application for waiver should be a long-term plan that articulates how the program will work to avoid a permanent need for the requested waiver. All waivers should be monitored and reviewed on an annual basis to determine suitability for renewal

- Programs should provide annual formal education for residents and staff on the adverse effects of sleep loss and fatigue and on the importance of and means for their prevention and mitigation

- Sponsoring institutions and programs should ensure that their practices promote and ensure that residents take the required sleep during extended duty periods

\section{Recommendation for moonlighting}

The ACGME should immediately amend its current requirements on moonlighting by:

- Requiring that any internal and external moonlighting for patient care adhere to the duty hour limits listed above (eg, 80 hours and all other limits), even if the program has received an exception to schedule longer hours

- Requiring that sponsoring institutions, if they choose to permit moonlighting, include provisions in resident contracts that a resident must request prospective, written permission from the program director for moonlighting, and resident performance will be monitored to ensure that there is no adverse effect of moonlighting on resident performance

\section{Recommendation on monitoring and overseeing}

ACGME and residency programs should ensure adherence to the current limits now, and to any new limits when implemented, by strengthening their current monitoring practices. To provide additional support, the Centers for Medicare and Medicaid Services and the Joint Commission should take an active overseeing role:

- The ACGME should maintain responsibility for duty hour monitoring and should enhance its procedures by including unannounced visits for monitoring duty hours and regular collection of sufficient data to understand when and why limits are violated

- Sponsoring institutions should provide for confidential, protected reporting of duty hour violations by residents through their compliance office or by an entity above the program level that does not have direct responsibility over the residency programs

- The ACGME should strengthen its complaint procedures to provide more confidentiality and protection to persons reporting violations of duty hours, as well as other violations of residency rules

- The Centers for Medicare and Medicaid Services should assess the reliability of ACGME procedures and data, and should sponsor periodic independent reviews of duty hour monitoring by the ACGME to determine the characteristics of and reasons for violations

- The Joint Commission should seek to ensure that duty hour monitoring is linked to broader activities to improve patient safety in hospitals, including the use of ACGME adherence data as part of the Joint Commission's hospital surveys and accreditation actions

\section{Recommendation on resident safety on the road}

The committee recommends that sponsoring institutions immediately begin to provide safe transportation options (eg, taxi or public transportation vouchers) for any resident who for any reason is too fatigued to drive home safely.

\section{Recommendation on resident workload}

To ensure that residency programs fulfill their core educational mission, the ACGME should require that institutions sponsoring residency programs appropriately adjust resident workload by:

- Providing support services and redesigning health care delivery systems to minimize the current level of residents' work that is of limited or no educational value, is 
extraneous to their graduate medical education program's educational goals and objectives, and can be done well by others

- Providing residents with adequate time to conduct thorough evaluations of patients and for reflective learning based on their clinical experiences

- The ACGME should require each residency review committee to define and then require appropriate limits on the caseload (eg, patient census, number of admissions, number of surgical cases to assist per day, cross-coverage) that can be assigned to a resident at a given time, taking into consideration the severity and complexity of patient illness and the level of resident competency

\section{Recommendation on resident supervision}

To increase patient safety and enhance education for residents, the ACGME should ensure that programs provide adequate, direct, onsite supervision for residents. The ACGME should require:

- The residency review committees, in conjunction with teaching institutions and program directors, to establish measurable standards of supervision for each level of doctor in training, as appropriate to their specialty

- First-year residents not to be on duty without having immediate access to a residency program-approved supervisory physician in-house

\section{Recommendation on training in effective patient handover}

Teaching hospitals should design, implement, and institutionalize structured handover processes to ensure continuity of care and patient safety.

- Programs should train residents and teams in how to handover their patients using effective communications

- Programs should schedule an overlap in time when teams transition on and off duty to allow for handovers

- The process should include a system that quickly provides staff and patients with the name of the resident currently responsible in addition to the name of the attending physician

\section{Recommendation on training in quality improvement}

Graduate medical education-sponsoring institutions should fully involve residents in their safety reporting, learning, and quality improvement systems, and this should become an important part of the resident educational experience.

\section{Recommendation on financial support for recommendations}

All financial stakeholders in graduate medical education, including the Centers for Medicare and Medicaid Services, Department of Veterans Affairs, Department of Defense, Health Resources and Services Administration, states and local governments, private insurers, and sponsoring institutions, should financially support the changes necessitated by the committee's recommendations to promote patient safety and resident safety and education, with special attention to safety net hospitals. An independent convening body should bring together all the major funders of graduate medical education to examine current financing methodologies and develop a coordinated approach to generate needed resources.

\section{Recommendation on future research and evaluation}

To gather the data necessary to monitor implementation of these recommendations and to prepare for future adjustments as needed to achieve the desired objectives, the ACGME should convene a meeting of stakeholders and potential funders to set priorities for research and evaluation projects. The Centers for Medicare and Medicaid Services, Agency for Healthcare Research and Quality, National Institutes of Health, Department of Defense, Department of Veterans Affairs, and other funders should support this work as a high priority.

\section{Appendix C}

Comparison of 2003 and 2011 Accreditation Council for Graduate Medical Education standards. Available from: www.acgme-2010standards.org/approved-standards.html. Accessed April 26, 2011.

\section{Appendix D Biographies of conference participants} James B Battles, PhD: Social Science Analyst for Patient Safety, Agency for Healthcare Research and Quality, Rockville, MD. Dr Battles did his undergraduate education at Miami University, and received his doctorate in medical education from the Ohio State University. In November 2000, Dr Battles joined the Agency for Healthcare Research and Quality (AHRQ) in Rockville, MD, as a social science analyst for patient safety, where he is a senior content specialist in patient safety for the patient safety initiative of the AHRQ. He has led the efforts of the 
AHRQ to advance the use of more proactive risk assessment and moving to risk-informed design of patient safety interventions. He also leads the efforts of the AHRQ in the assessment of patient safety culture and improving team work in collaboration with the Department of Defense. Dr Battles is the AHRQ project officer for the national implementation of a project to eliminate central line-associated infections in intensive care units throughout the US. He is an internationally recognized expert in the area of patient safety, having authored numerous articles and book chapters in the past several years. Dr Battles was the AHRQ co-project officer for the Institute of Medicine resident duty hours study and report. Prior to coming to the AHRQ, he was professor of medical education at The University of Texas Southwestern Medical Center at Dallas, where he was coprincipal investigator for the medical event reporting system for transfusion medicine funded by the National Institutes of Health, which has served as a prototype for a national system of reporting near-miss events in health care.

Maureen Bisognano: Ms Bisognano is President and Chief Executive Officer of the Institute for Healthcare Improvement in Boston MA, an independent not-for-profit organization helping to lead the improvement of health care throughout the world. She is a prominent authority on improving health care systems, whose expertise has been recognized by her elected membership to the Institute of Medicine of the National Academy of Sciences and by her appointment to the Commonwealth Fund's commission on a high performance health system, among other distinctions. Ms Bisognano advises health care leaders around the world, is a frequent speaker at major health care conferences on quality improvement, and is a tireless advocate for change. She is also an instructor of medicine at Harvard Medical School and a research associate in the Division of Social Medicine and Health Inequalities at the Brigham and Women's Hospital. Ms Bisognano began her career in health care in 1973 as a staff nurse at Quincy Hospital in Massachusetts. She was director of nursing at Quincy Hospital in 1981-1982, director of patient services in 1982-1986, and chief operating officer in 1986-1987. She holds a Bachelor of Science degree from the State University of New York and a Master of Science degree from Boston University.

John Brockman: Taking time off before his fourth year of medical school at Case Western Reserve University in Cleveland, $\mathrm{OH}$, John Brockman is privileged to serve as the sixtieth national president of the American Medical Student Association (AMSA). A native of Omaha, NE,
John Brockman graduated Phi Beta Kappa from Truman State University, where he studied biology and business administration. While at Truman, he led one of the largest premedical AMSA chapters organizing events around World AIDS Day, S-CHIP reauthorization, covering the uninsured, and developing student leaders. He has served as a premedical trustee for AMSA, organized the first premedical leadership institute, been secretary of the AMSA board of trustees and, most recently, vice president of internal affairs.

Claire C Caruso, RN, PhD: Dr Caruso is a Research Health Scientist at the National Institute for Occupational Safety and Health (NIOSH) in Cincinnati, OH. The focus of her 11 years of work at NIOSH is the influence of shift work and long working hours on health and safety and strategies to prevent risks. She is a member of the National Occupational Research Agenda (NORA) health care social assistance council and the NIOSH health care social assistance steering committee that both work to reduce occupational health and safety risks in this industrial sector. She led the NORA long working hours team that published a research agenda for long working hours in 2006, and has 16 publications on this topic. She provides consultation to external requestors about working hour issues. Dr Caruso completed a PhD in nursing in 1999 at the University of Michigan. Her PhD program focused on health and safety risks associated with demanding work schedules and the underlying sleep and circadian rhythm research that provides evidence for this topic. Before embarking on her $\mathrm{PhD}$ program, she worked for many years as a registered nurse and progressed through that career path from staff nurse to nurse manager to clinical nurse specialist. This work occurred in hospitals including a large medical center with residency programs.

David I Cohen, MD, MSc: Dr Cohen is currently Executive Vice President for Clinical and Academic Development, and Senior Vice Chairman of the Department of Medicine at Maimonides Medical Center, Brooklyn, NY. Dr Cohen received his $\mathrm{BA}$ and $\mathrm{MD}$ degrees from the University of Pennsylvania and an MSc in epidemiology and health from McGill University, where he was a Robert Wood Johnson clinical scholar in 1977-1979. After completing his residency in internal medicine in New York and his clinical research fellowship in Montreal, he joined the faculty of Case Western Reserve University and was appointed chief of the Division of General Internal Medicine at Cleveland Metropolitan General Hospital in 1981. In that position, he helped to develop the "firm system" as a model for patient care, clinical education, 
and health services research. In 1986 he returned to New York to accept a position at Mt Sinai Medical Center as director of ambulatory care and associate dean for graduate medical education. In 1988-1990 he was vice president of medical operations for the New York City Health and Hospitals Corporation. In 1990-1991, he served as deputy dean of clinical affairs at the City University of New York Sophie Davis Medical School, and in 1991-1998 served as the first full time medical director at Bellevue Hospital Center, New York, NY.

Jordan J. Cohen, MD: Dr Cohen is Professor of Medicine and Public Health at George Washington University and president emeritus of the Association of American Medical Colleges (AAMC). He is a director of the Washington Advisory Group and also serves as chairman of the board of the Arnold P Gold Foundation for Humanism in Medicine. As president and chief executive officer of the AAMC in 1994-2006, Dr Cohen led the association's support and service to the nation's medical schools and teaching hospitals. He launched new initiatives in each of the association's mission areas of education, research, and patient care, expanded and modernized the AAMC's services for medical students, applicants, residents, and constituents, strengthened the association's communications, advocacy, and data-gathering efforts, and established many initiatives for improving medical education and clinical care. As the voice of academic medicine for more than a decade, Dr Cohen has also spoken extensively on the need to promote greater racial and ethnic diversity in medicine, to uphold professional and scientific values, and to transform the nation's health care system.

Prior to his leadership of the AAMC, he served as dean of the medical school and professor of medicine at the State University of New York at Stony Brook, and as president of the medical staff at University Hospital. Before that, Dr Cohen was professor and associate chairman of medicine at the University of Chicago Pritzker School of Medicine, and physician-in-chief and chairman of the Department of Medicine at the Michael Reese Hospital and Medical Center. Dr Cohen is a graduate of Yale University and Harvard Medical School, and completed his postgraduate training in internal medicine on the Harvard service at the Boston City Hospital. He also completed a fellowship in nephrology at the Tufts-New England Medical Center. He has authored more than 100 publications and is a former editor of Kidney International's nephrology forum.

John R Combes, MD: Dr Combes is Senior Vice President of the American Hospital Association and the President of the Center for Healthcare Governance, an American Hospital Association-affiliated organization. The Center for Healthcare Governance is a dynamic community of board members, executives, and opinion leaders dedicated to advancing excellence, innovation, and accountability in health care governance through education, tool development, and research. Dr Combes also serves as senior fellow at the Hospital Research and Education Trust, and in that role focuses on quality and leadership issues in patient safety, end of life care, and clinical performance improvement. Dr Combes received his medical degree from Cornell University in New York and undertook his postgraduate training at Boston City Hospital. He is certified in internal medicine by the American Board of Internal Medicine and has management certification from the American College of Physician Executives. Dr Combes has held several senior management positions in a variety of health care organizations. More recently, he has been serving on several national advisory groups on medical ethics, palliative care, and reduction of medication errors. He serves as principal investigator for an Agency for Healthcare Research and Quality national initiative to reducing central line infections through the use of a comprehensive unit-based patient safety approach pioneered by Johns Hopkins University.

Charles A Czeisler, PhD, MD: Dr Czeisler is the Baldino Professor of Sleep Medicine and Director of the Division of Sleep Medicine at Harvard Medical School and Chief of the Division of Sleep Medicine in the Department of Medicine at Brigham and Women's Hospital in Boston, MA. He is an affiliate faculty member in the neuroscience program at Harvard Medical School and the health science and technology program at Harvard Medical School/ Massachusetts Institute of Technology. Dr Czeisler graduated magna cum laude with a degree in biochemistry and molecular biology from Harvard College, where he was inducted into Phi Beta Kappa in 1999. He received his PhD in neurobehavioral and biobehavioral sciences and his MD from Stanford University. He is a past president of the Sleep Research Society where he chaired the Presidential Task Force on Sleep and Public Policy; a fellow of the American Society for Clinical Investigation and of the Association of American Physicians; a diplomate of the American Board of Sleep Medicine; a fellow of the Royal College of Physicians (London) and an elected member of the American Clinical and Climatological Association and the Institute of Medicine of the National Academies. Dr Czeisler has more than 30 years of experience in the field of basic and applied research on the physiology of the human circadian timing system 
and its relationship to the sleep-wake cycle. Dr Czeisler has published over 140 original reports in peer-reviewed journals, more than 90 review articles, and five books/monographs and numerous research abstracts. He has been a member of the editorial boards of American Journal of Medicine, Journal of Biological Rhythms, and Sleep. Dr Czeisler has served on and consulted for a number of national and international advisory committees, including the National Institutes of Health, the Institute of Medicine, the National Academy of Sciences, the Sleep Research Society, the Nuclear Regulatory Commission, the Air Force Office of Scientific Research, the Air Transport Association, and the Federal Motor Carrier Safety Administration of the US Department of Transportation. In 2008, Dr. Czeisler served as a special consultant to the Massachusetts Special Commission on Drowsy Driving and currently chairs the Sleep Disorders Research Advisory Board for the National Center for Sleep Disorders Research of the National Heart, Lung and Blood Institute. The views expressed are solely the opinion of the author and not of the Harvard Medical School (for which the author serves as a member of the faculty), the Brigham and Women's Hospital or Partners HealthCare System, Inc. (where the author is employed) or the NIH Sleep Disorders Research Advisory Board (which the author Chairs as a Special government Employee).

Jennifer Domingo, MD: Dr Domingo is Associate Resident Program Director, Ob-Gyn, Santa Clara Valley Medical Center, San Jose, CA. She attended medical school at the University of California, San Francisco, and completed her obstetrics and gynecology residency in 2000 at Santa Clara Valley Medical Center in San Jose, CA, where she has stayed on staff and currently works as an obstetrics and gynecology generalist attending. In addition to her clinical work, she currently serves as the associate program director for the obstetrics and gynecology residency program and has been active in this role for the last five years. In addition to this role, she also plays an active role in department committees, including quality assurance and quality improvement in gynecology and surgical simulation in obstetrics and gynecology. Her other academic interests include incontinence and reconstructive pelvic surgery.

Edward J Dunn, MD, ScD: Dr Dunn is the Associate Chief of Performance Improvement for the Lexington Veterans Affairs Medical Center and faculty in the College of Public Health, Department of Health Policy and Management at the University of Kentucky in Lexington, KY. Dr Dunn earned a BA degree from the University of Notre
Dame in 1969 and an MD from Wayne State University in 1973. After completing his residency in surgery at the LSU Medical Center in 1978 and in thoracic surgery at Vanderbilt University in 1980, he practiced cardiac and thoracic surgery in 1980-1998 in the private sector and in 2001-2003 in a public health system. From 1995 through 2000, Dr Dunn earned advanced degrees at the Northwestern Kellogg School of Management, Harvard Kennedy School of Government, and the Harvard School of Public Health. Dunn received a doctor of science degree in health policy and management from the Harvard School of Public Health in June 2009. His doctoral studies focused on the organizational culture of teamwork coordination and innovation in surgical services. In 2000-2001, Dr Dunn was a Robert Wood Johnson health policy fellow in Washington, DC, and worked in the first session of the 107th Congress as majority legislative staff for Senator Edward M Kennedy, chairman of the US Senate Committee on Health, Education, Labor and Pensions. In 2001-2003, Dr Dunn was the patient safety director at the Cambridge Health Alliance and served as their representative on the Massachusetts Coalition for the Prevention of Medical Errors. From 2003 to 2009, Dunn was the director of policy and clinical affairs for the Veterans Affairs National Center for Patient Safety in Ann Arbor, MI, where he completed the multiple initiatives.

Helen Haskell: Ms Haskell is founder and president of Mothers Against Medical Error, a South Carolina-based group dedicated to improving patient safety and providing support for patients who have experienced medical injury. For Ms Haskell, patient safety is a calling to which she was brought into by the death of her 15-year-old son Lewis as a result of medical error in a South Carolina teaching hospital. In 2005, Ms Haskell helped put together a coalition of patients, policymakers, and health care providers to pass the Lewis Blackman Patient Safety Act, the first of several South Carolina legislative initiatives addressing health care safety and transparency. In 2007, the state of South Carolina created a Lewis Blackman chair of patient safety and clinical effectiveness, an endowed professorship named in honor of her deceased son. Ms Haskell is actively involved in patient safety and quality improvement efforts in South Carolina, throughout the US, and internationally, on such topics as medical education reform, patient-activated rapid response, infection prevention, medical error disclosure, and patient empowerment and education. In 2009, she was named one of Modern Healthcare's "100 Most Powerful People in Healthcare". She is a board member of Consumers Advancing Patient Safety (a patient safety 
organization) and codirector of the nonprofit Empowered Patient Coalition. She is coauthor, with Julia Hallisy, of "The Empowered Patient Guide to Hospital Care for Patients and Families".

Joel T Katz, MD: A graduate of Earlham College and the Johns Hopkins University School of Medicine, Dr Katz is an infectious diseases consultant, Director of the internal medicine residency program, and Vice Chair for Education at Brigham and Women's Hospital. He is an Assistant Professor of Medicine at the Harvard Medical School. He also holds the Marshall A Wolf chair in medical education. Academic interests include patient safety and curriculum innovation, including in areas of physical skills and utilizing fine arts to improve medical care.

Christopher P Landrigan, MD, MPH: Dr Landrigan is Assistant Professor of Pediatrics and Medicine at Harvard Medical School, Director of the Sleep and Patient Safety Program at Brigham and Women's Hospital, and a practicing pediatric hospitalist. He has 12 years of experience studying the quality and safety of hospital care. His research has evaluated efficiency and outcomes of care in pediatric hospitalist systems, as well as patient safety across pediatric and adult inpatient settings. Over the past several years, Dr Landrigan has led a series of studies evaluating the relationship between resident depression and patient safety, the effects of computerized order entry systems on rates of medication errors, and the relationship between resident handoffs and error. However, his primary focus has been studying the effects of resident sleep deprivation on patient safety. Dr Landrigan was a founding member of the Harvard Work Hours, Health, and Safety Group, and lead author of a randomized controlled trial reporting that interns working traditional 24-30-hour shifts made 36\% more serious medical errors, and five times as many serious diagnostic errors, as interns whose scheduled work was limited to 16 consecutive hours. He subsequently led a national cohort study and an intensive tricenter study which demonstrated that ACGME duty hour standards have been ineffective in reducing the risk of fatigue-related error due to inherent limitations in ACGME standards, and poor compliance with them. His current work focuses on evaluating the effectiveness of diverse approaches to reducing fatigue-related error, improving handovers of care, and translating safety research into policy and practice.

Lucian Leape, MD: Dr Leape is an Adjunct Professor in the Department of Health Policy and Management at the Harvard School of Public Health. Prior to joining the faculty at Harvard in 1988, he was professor of surgery and chief of pediatric surgery at Tufts University School of Medicine. He is a graduate of Cornell University and Harvard Medical School. Dr Leape is internationally recognized as a leader of the patient safety movement, starting with the publication of his seminal article entitled "Error in Medicine" in 1994. His subsequent research demonstrated the application of systems theory to the prevention of adverse drug events through computerized physician order entry and other process changes. Dr Leape was a member of the Institute of Medicine committee that published "To Err is Human" in 1999 and "Crossing the Quality Chasm" in 2001. He has published over 135 papers on patient safety and quality of care. In 2004, he received the John Eisenberg patient safety award from the Joint Commission on Accreditation of Healthcare Organizations and National Quality Forum. In 2006, Modern Healthcare named him as one of the 30 people who have had the most impact on health care in the past 30 years. In 2007, the National Patient Safety Foundation established the Lucian Leape Institute to further strategic thinking in patient safety.

Michelle Lefkowitz: Ms Lefkowitz is a technical advisor in the Division of Acute Care at the Centers for Medicare and Medicaid Services in Baltimore. She is the senior policy analyst for Medicare payment policy for graduate medical education programs, but also works on a number of other Medicare hospital payment policies under the inpatient prospective payment system. Ms Lefkowitz has been at the Centers for Medicare and Medicaid Services for close to 11 years and has received a masters in business administration with a concentration on health care management from Loyola College in Maryland.

Arthur Aaron Levin, MPH: Mr Levin is cofounder and Executive Director of the Center for Medical Consumers, a New York City-based non-profit organization committed to informed consumer and patient health care decision-making, patient safety, evidence-based, highquality medicine and health care system transparency. The organization receives no funding from the drug, device or health care industry. Mr Levin was a member of the Institute of Medicine's Committee on the quality of health care that published the "To Err is Human" and "Crossing the Quality Chasm" reports. He also served on the Institute of Medicine committee that evaluated the federal quality effort and made recommendations to Congress in its report "Leadership Through Example". He was a member of the Institute of Medicine's subcommittee on performance measures, which reported to the committee on redesigning health insurance benefits, payment, and performance improvement 
program. Levin was also a member of the committee that issued a letter report in October 2007 entitled "Opportunities for coordination and clarity to advance the national health information agenda" and on the committee that wrote "Knowing what works in health care: A roadmap for the nation" published in fall 2008. In spring 2009, Levin was a member of the Institute of Medicine committee on comparative effectiveness research priorities, charged with advising the secretary of the Health and Human Services on priorities for CER funded by ARRA. He is a member of the Institute of Medicine Board for Health Care Services Mr Levin is currently co-chair of the NCQA Committee on Performance Measures that is charged with developing performance measures applicable to health plans, PPOs and most recently physician practices.

Steven W Lockley, PhD: Dr Lockley is an Assistant Professor of Medicine in the Division of Sleep Medicine at Harvard Medical School and an Associate Neuroscientist in the Division of Sleep Medicine at Brigham and Women's Hospital. He also holds adjunct associate professor positions at Warwick Medical School, Monash University, and the Woolcock Institute of Medical Research. Dr Lockley's research focuses on basic and applied aspects of human circadian biology and sleep medicine using a translational approach which uses a range of techniques including epidemiology, field-based physiological and outpatient studies, and intensive inpatient physiological monitoring. As a founding member of the Harvard Work Hours Health and Safety Group, Dr Lockley has led several studies to assess sleep, sleepiness, and sleep disorders in a range of professions, including medical residents, police officers, and firefighters. These studies include interventions to test the impact of reducing work hours on sleep and medical performance in medical residents in both the US and UK.

Kavita Patel, MD, MSHS: Dr Patel is currently Director of the health policy program at the New America Foundation, a nonpartisan think tank in Washington, DC. She is a board-certified internal medicine physician who has dedicated her life to bringing the stories and lessons learned from her clinical experiences to policymakers and the people working on shaping the future of our health care system. Her expertise spans a number of sectors, including delivery system reform and equipping clinical teams with the skills necessary to respond to our changing health care system. She is most recently the director of policy for the White House Office of Public Engagement and Intergovernmental Affairs where she worked on health care reform legislation.
Prior to that, she was the deputy staff director for the senate health, education, labor, and pensions committee under the leadership of Senator Edward M Kennedy. Prior to her time in Washington, Dr Patel was a clinical instructor at UCLA and an associate scientist at the RAND Corporation, focusing on research in health care quality. She completed a prestigious fellowship in the Robert Wood Johnson clinical scholars program at UCLA with a focus on community-based participatory research. She received her medical training at the University of Texas Health Science Center and Oregon Health and Sciences University where she served as a chief resident in internal medicine. During medical school, she served as the national president of the American Medical Student Association.

Ann Louise Puopolo, BSN, RN: Ms Puopolo is the Director of Loss Prevention and Patient Safety at the Controlled Risk Insurance Company and Risk Management Foundation of the Harvard Medical Institutions (CRICO/ $\mathrm{RMF}$ ). CRICO/RMF is a patient safety and medical malpractice company owned by and serving the Harvard medical community since 1976. CRICO/RMF's proven ability to combine strong insurance protection with expert legal services and best practices in patient safety enables physicians, institutions, and employees to focus their considerable expertise on their patients and their research. Ms Puopolo received her BSc in nursing from Vanderbilt University and practiced as a critical care nurse at Boston's Beth Israel Deaconess Hospital. She has over 16 years of health services research experience and became the project director of a Robert Wood Johnson Foundation-funded study examining decision-making in critically ill patients near the end of life across five US hospitals. Following this, Ms Puopolo served as research director at Brigham and Women's Hospital, Division of General Medicine/ Primary Care and the Department of Health Policy and Management at Harvard School of Public Health. During her 10-year tenure, Ms Puopolo directed several projects funded by $\mathrm{CRICO} / \mathrm{RMF}$, including the ambulatory medicine quality improvement project, and the Harvard project on care improvement for the critically ill. Most recently, Ms Puopolo directed the Malpractice Insurers' Medical Error Surveillance and Prevention Study funded by the Agency of Health Care Research and Quality and designed to examine closed malpractice cases across five self-insured medical malpractice carriers. The goals of this study were to identify factors that most frequently contribute to error, and to design, implement, and measure a series of targeted interventions. 
Farbod Raiszadeh, MD, PhD: Dr Raiszadeh is currently a fellow in cardiovascular medicine at Montefiore Medical Center, University Hospital of Albert Einstein College of Medicine. He holds board certification in internal medicine, having completed residency training at St Luke's Roosevelt Hospital Center, an affiliate of Columbia University College of Physicians and Surgeons. He also holds a PhD degree from Cornell University, an MD degree from Tehran University of Medical Sciences, and is President of the Committee of Interns and Residents/Service Employees International Union Healthcare, a national union representing about 13,000 interns, residents, and fellows in the US.

Wendy Reid: Professor Reid trained as an obstetrician and gynecologist and was appointed as a consultant and honorary senior lecturer to the Royal Free Hospital in 1994. She became a fellow of the Royal College of Obstetricians and Gynaecologists in 1996, and is the senior elected fellow representing London on the council of the Royal College of Obstetricians and Gynaecologists. Her clinical interests are vulval disease and childbirth trauma. She has a long-standing interest in medical education and was fortunate to have this formally recognized in her consultant appointment with a dedicated session for postgraduate education. She became one of the first training program directors following the implementation of the Calman reorganization of specialty training in 1995, and went on to chair the North Central London specialist training committee. She became an associate postgraduate dean in 2001 and was responsible for postgraduate training in anesthetics and pediatrics across London of approximately $30 \%$ of the UK trainees in these specialties. In 2004, she was appointed as a postgraduate dean in London, providing educational leadership across North Central and North East London. She is the national lead dean for general surgery, plastic surgery, and pediatrics and, as such, manages workforce planning, curriculum implementation, trainee recruitment, and progress with the Royal colleges. She was appointed to an honorary chair at Bart's and The Royal London in 2009. Professor Reid was appointed as the national clinical advisor to the Department of Health for the European working time directive in December 2008. She advised government ministers, working with leaders in the medical profession and senior health service managers to ensure safe patient care as trainee doctors' hours reduced to 48 hours per week in August 2009. She was a member of the advisory expert group for the independent report from Medical Education England on the impact of the working time regulations on postgraduate training, entitled "Time to train".

Paul M Schyve, MD: Dr Schyve is Senior Vice President of the Joint Commission. In1989-1993, he was Vice President for Research and Standards, and in 1986-1989, was director of standards at the Joint Commission. Prior to joining the Joint Commission, Dr Schyve was the clinical director of the State of Illinois Department of Mental Health and Developmental Disabilities. Dr Schyve is certified in psychiatry by the American Board of Psychiatry and Neurology, and is a distinguished life fellow of the American Psychiatric Association. He is a founding advisor of Consumers Advancing Patient Safety, the chair of the ethical force oversight body of the Institute of Ethics at the American Medical Association, a former trustee of the United States Pharmacopeial Convention, and a former member of the board of directors of the National Alliance for Health Information Technology. He has served on numerous advisory panels for the Centers for Medicare and Medicaid Services, the Agency for Healthcare Research and Quality, and the Institute of Medicine. Dr Schyve has published in the areas of psychiatric treatment and research, psychopharmacology, quality assurance, continuous quality improvement, health care accreditation, patient safety, health care ethics, and cultural and linguistic competence. Dr Schyve received his undergraduate degree from the University of Rochester, where he was elected to Phi Beta Kappa. He completed his medical education and residency in psychiatry at the University of Rochester, and has subsequently held a variety of professional and academic appointments in the areas of mental health and hospital administration, including as director of the Illinois State Psychiatric Institute and clinical associate professor of psychiatry at the University of Chicago.

David B Sweet, MD: Dr Sweet is Professor of Medicine at the Northeastern Ohio Universities College of Medicine. He received his MD degree from Ohio State University in 1977. He completed his internship and residency in internal medicine at Akron City Hospital in 1980. He served on the faculty at Akron City Hospital (now Summa Health System) and became associate program director of the internal medicine residency in 1984. Dr Sweet was appointed Program Director in 2004. Particular areas of interest have been patient and resident safety, as well as the education of residents in a team-based approach to patient care. Under Dr Sweet's leadership, the Summa Health System/Northeastern Ohio Universities College of Medicine (NEOUCOM) internal medicine residency has been redesigned since 2006 to limit 
resident duty shifts to a maximum of 16 hours while not reducing resident patient volumes or increasing its resident complement. The Summa/NEOUCOM internal medicine residency has participated in the Residency Review Committee for Internal Medicine Educational Innovation project since 2006.

James F Whiting, MD: Dr Whiting is currently Director of surgical education at Maine Medical Center. Dr Whiting was educated as an undergraduate at Harvard College, graduated in 1981, and received his MD degree from the Albert Einstein College of Medicine in 1986. He then did his surgical training at the Brigham and Women's Hospital in Boston, before pursuing a fellowship in transplantation surgery at Rush Presbyterian St Lukes Hospital in Chicago. After his fellowship, he served on the faculty at the University of Cincinnati Medical Center, caring for liver and kidney transplant patients until 2000 when he moved to Maine to become the surgical director of the Maine Transplant Program where he continues to practice and retains that title. In 2008, Dr Whiting became director of surgical education and assumed leadership of the surgical residency program at Maine Medical Center. Until that time, his interest in medical education has been real, but informal. The experience of becoming a program director has led Dr Whiting to re-examine some long-held beliefs about the nature of medical training, the effects of surgical culture on patient care and patient safety, and the direction of medicine in general. He and others are currently working to channel some of those insights into a safer, better environment for surgical training at Maine Medical Center.

Veronica Wilbur, RN, BSN, MBA: With 30 years of nursing experience, including 15 years of management and administrative responsibilities, Ms Wilbur is the Senior Director of Island Peer Review Organization's hospital compliance review program. The hospital compliance program reviews hospital compliance with resident duty hours both statewide and nationally. Her management and administrative background includes case management, discharge planning, risk/quality management, and project development experience in five acute care facilities. Ms Wilbur has extensive experience in data analysis and report preparation to meet regulatory needs. She has experience with the Joint Commission on Accreditation of Healthcare Organizations and the New York State Department of Health surveys, as well as preparation and team discussion for Centers for Medicare and Medicaid Services surveys and Safe Medical Device Act regulations. Ms Wilbur has worked with graduate medical education offices statewide to meet the 405 and ACGME regulations. Ms Wilbur holds a BSc in nursing from Niagara University and an MBA from State University of New York in Albany. Additionally, she holds a certification in health care compliance.

Barbara O Wynn: Ms Wynn, Senior Health Policy Analyst at the Rand Corporation, has been intimately involved with Medicare payment policies and graduate medical education financing for more than 30 years. Ms Wynn joined Rand Corporation in 1999 after 24 years with the Health Care Financing Administration (the predecessor agency to the Centers for Medicare and Medicaid Services). Since coming to Rand Corporation, she has been principal investigator for several Health and Human Services-funded projects related to graduate medical education, including a research report that formed the basis for the Council on Graduate Medical Education's fifteenth report, reports addressing implementation issues related to the Childrens' Hospital graduate medical education fund, and studies examining alternative ways of financing graduate medical education and variation in the Medicare support for direct graduate medical education costs. Current work includes a Medicare Policy Advisory Commission-funded study that is examining how well internal medicine residency programs are providing physicians-in-training with the skills and proficiencies that are new or have increased importance for patient care. While at the Health Care Financing Administration, Ms Wynn was directly involved with Medicare payment policies related to graduate medical education, beginning with the initial establishment of direct graduate medical education per resident amounts in 1986 though the regulations implementing the graduate medical education provisions in the Balanced Budget Act of 1997. During her last five years at Health Care Financing Administration, Ms Wynn represented Health Care Financing Administration on the Council on Graduate Medical Education and chaired the financing workgroup of the secretary for Health and Human Services task force on the future of academic health centers.

Alexander B Blum, MD: Dr Blum is a Ruth Kirschstein National Research Service Award health policy fellow at Mount Sinai School of Medicine. He is enrolled in a masters in the public health program at the Johns Hopkins Bloomberg School of Public Health. He graduated in 2005 from the Howard University College of Medicine and in 2008 from the Community Health and Advocacy Track at UCLA Mat- 
tel children's pediatric residency program. Prior to joining Mount Sinai, he was a visiting professor of pediatrics at UCLA-Olive View Medical Center. Dr Blum was a board member and former national field director for Doctors for America, and is on the board of directors of the National Physicians Alliance.

Sandra Shea: Ms Shea is policy director of the Committee of Interns and Residents/Service Employees International Union Healthcare, a national union of resident physicians with 13,000 members in more than 60 public and private teaching hospitals. She also serves as program director of the nonprofit CIR Policy and Education Initiative. A graduate of the University of Massachusetts, she has more than 30 years of experience with resident physician training issues.

A report from this conference at Harvard Medical School is available at www.cirpei.org.

\section{Publish your work in this journal}

Nature and Science of Sleep is an international, peer-reviewed, open access journal covering all aspects of sleep science and sleep medicine, including the neurophysiology and functions of sleep, the genetics of sleep, sleep and society, biological rhythms, dreaming, sleep disorders and therapy, and strategies to optimize healthy sleep. The journal welcomes

\section{Dovepress}

original research, clinical \& epidemiological studies, reviews \& evaluations, case reports and extended reports. The manuscript management system is completely online and includes a very quick and fair peerreview system, which is all easy to use. Visit http://www.dovepress.com/ testimonials.php to read real quotes from published authors. 